\title{
1 A review of microplastics aggregation in aquatic environment: \\ 2 Influence factors, analytical methods, and environmental implications
}

4 Xinjie Wang ${ }^{\mathrm{a}}$, Nanthi Bolan ${ }^{\mathrm{b}}$, Daniel C.W. Tsang ${ }^{\mathrm{c}}$, Sarkar Binoy ${ }^{\mathrm{d}}$, Lauren Bradney ${ }^{\mathrm{b}}$,

$6{ }^{a}$ Key Laboratory of Water and Sediment Sciences of Ministry of Education, State Key

7 Laboratory of Water Environment Simulation, School of Environment, Beijing Normal

8 University, Beijing 100875, PR China

$9 \quad{ }^{b}$ Faculty of Science, University of Newcastle, Callaghan, NSW, Australia

$10{ }^{c}$ Department of Civil and Environmental Engineering, The Hong Kong Polytechnic

11 University, Hung Hom, Kowloon, Hong Kong, China

$12{ }^{d}$ Lancaster Environment Centre, Lancaster University, Lancaster, LA1 4YQ, United 13 Kingdom

14

15

16 Corresponding Author

17 *Phone: +86-10-5880-7612; e-mail: liyang_bnu@ @bnu.edu.cn (Y.L.). 


\section{Highlights}

- The aggregation of MPs in real aquatic environment is far from fully understood.

- Sampling and analyzing methods for studying MP aggregation were summarized.

- Influence factors and environmental implications of MP aggregation were reviewed.

- MP aggregation in the field and their temporal stability deserve extensive research.

- Laboratory studies should use MPs representing those in real aquatic environment.

\section{Graphical abstract}

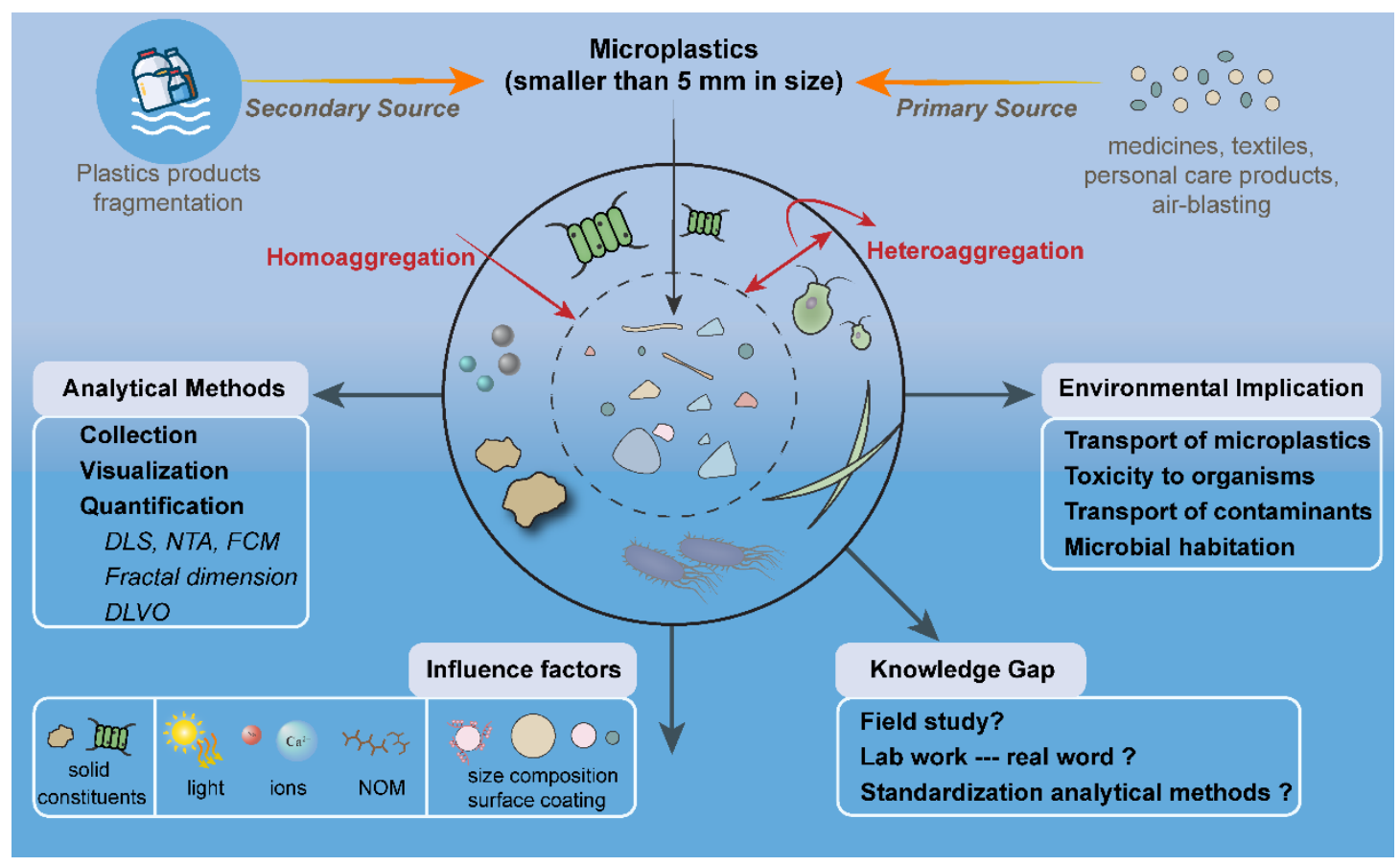


28 Abstract: A large amount of plastic waste released into natural waters and their 29 demonstrated toxicity have made the transformation of microplastics (MPs; $<5 \mathrm{~mm}$ ) and 30 nanoplastics (NPs; $<100 \mathrm{~nm}$ ) an emerging environmental concern. Aggregation is one of

31 the most important environmental behaviors of MPs, especially in aquatic environments, 32 which determines the mobility, distribution and bioavailability of MPs. In this paper, the 33 sources and inputs of MPs in aquatic environments were first summarized followed by the 34 analytical methods for investigating MP aggregation, including the sampling, visualization, 35 and quantification procedures of MP' particle sizes. We critically evaluated the sampling 36 methods that still remains a methodological gap. Identification and quantification of MPs 37 were mostly carried out by visual, spectroscopic and spectrometric techniques, and 38 modeling analysis. Important factors affecting MP aggregation in natural waters and 39 environmental implications of the aggregation process were also reviewed. Finally, 40 recommendations for future research were discussed, including (1) conducting more field 41 studies; (2) using MPs in laboratory works representing those in the environment; and (3) 42 standardizing methods of identification and quantification. The review gives a 43 comprehensive overview of current knowledge for MP aggregation in natural waters, 44 identifies knowledge gaps, and provides suggestions for future research.

45 Keywords: Microbead, Stability, Detection methods, Microbial habitation, Contaminant 46 vector

47 Abbreviations

48 nanoplastics (NPs)

49 microplastics (MPs)

50 polystyrene (PS) 
51 polyethylene (PE)

52 polypropylene (PP)

53 polyvinyl chloride (PVC)

54 poly(methyl methacrylate) (PMMA)

55 amino-modified PS NPs (PSNPs-NH $\left.{ }_{2}\right)$

56 carboxyl-modified PS NPs (PSNPs-COOH)

57 ultraviolet (UV)

58 humic acid (HA)

59 laser diffraction (LD)

60 fractal dimensions $\left(\mathrm{D}_{\mathrm{f}}\right)$

61 flow cytometry (FCM)

62 attachment efficiency $(\alpha)$

63 hydrodynamic diameter $\left(\mathrm{D}_{\mathrm{h}}\right)$

64 exopolymeric substances (EPS)

65 field flow fractionation (FFF)

66 dynamic light scattering (DLS)

67 atomic force microscopy (AFM)

68 dissolved organic matter (DOM)

69 extended DLVO-theory (eDLVO)

70 nanoparticle tracking analysis (NTA)

71 scanning electron microscopy (SEM)

72 energy dispersive spectroscopy (EDS)

73 wastewater treatment plants (WWTPs)

74 hydrodynamic chromatography (HDC)

75 transmission electron microscopy (TEM)

76 critical coagulation concentration (CCC) 
Derjaguin-Landau-Verwey-Overbeek (DLVO)

78 Fourier-transform infrared spectroscopy (FTIR)

79 asymmetrical flow field-flow fractionation (AF4)

\section{Introduction}

Microplastics (MPs) and nanoplastics (NPs) are defined as plastic particles with diameters $<5 \mathrm{~mm}$ and $<100 \mathrm{~nm}$, respectively (Feng et al., 2020). Scientists agree that the pollution of MPs in marine and freshwater environments have potential adverse impacts on aquatic organisms, marine ecosystems and even human health (Castelvetro et al., 2020;

Wang and Wang, 2018). Regulators and researchers currently assess the environment risk of MPs relying upon their ecotoxicity tests and environmental fate modeling (Karbalaei et al., 2018). Aggregation of MPs is an important physical-chemical process dominating the transport behavior and overall fate of MPs in aquatic environments (Alimi et al., 2018). Recent investigations on MP aggregation have focused on simulated natural waters in laboratory, while the process in complex heterogeneous media or in natural waters is largely unknown (Singh et al., 2019). Adequate experimental protocols and environmental fate models are needed to develop for theoretically understanding and quantifying the aggregation process of the MP pollutants (Praetorius et al., 2020).

Aggregation involves the transport of two particles toward each other to collide, followed by attachment (Zhang, 2014). This can occur between the same type of MPs (homoaggregation) or different types of particles (heteroaggregation) (Alimi et al., 2018). Compared with the homoaggregation of MPs, the heteroaggregation of MPs with other solid constituents such as natural minerals and seaweeds is more prone to occur in natural waters driving the floating, sedimentation, and resuspension processes of MPs (Long et al., 
101 2017; Oriekhova and Stoll, 2018; Singh et al., 2019). The organism-associated aggregation 102 of MPs/NPs have been widely reported, as shown in Fig.1 a-e. Plastic surfaces commonly 103 contain hydrophobic functional groups that facilitate the adsorption of dissolved organic 104 matter (DOM) and organisms, especially algae and bacteria (Zhang et al., 2020). Microbial 105 habitation and biofilm formation are common on MP surface in natural waters (Harrison et 106 al., 2018). Apart from organism-associated MP aggregates, organic matter (e.g., alginate) 107 (Fig. 1 f), layered clay minerals (e.g., suspended sediment (Fig. 1 g), $\mathrm{Fe}_{2} \mathrm{O}_{3}$ ), and 108 nanoparticles also could aggregate with MPs (Li et al., 2020). Because of the inherently 109 higher system complexity, studies on heteroaggregation of MPs are still scarce (Oriekhova 110 and Stoll, 2018). 

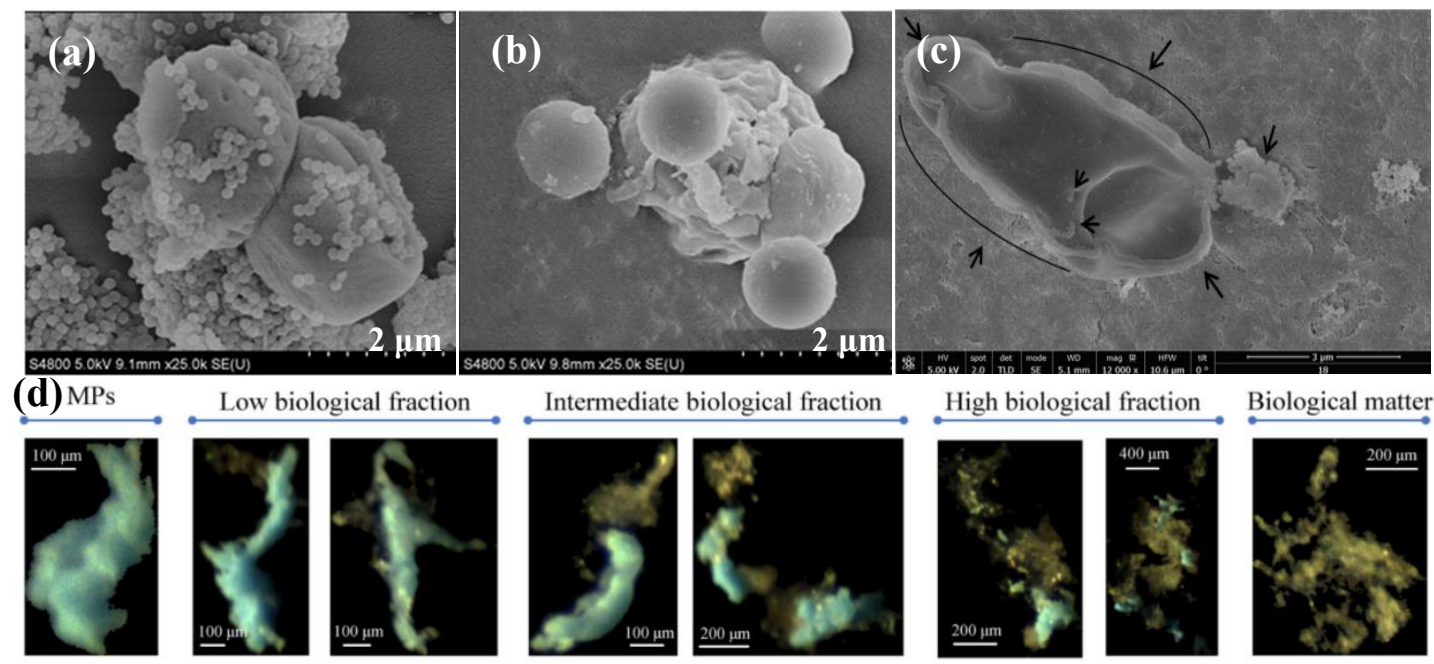

Low biological fraction

Intermediate biological fraction

High biological fraction Biological matter

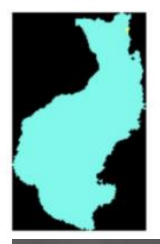

(e)

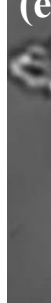

○
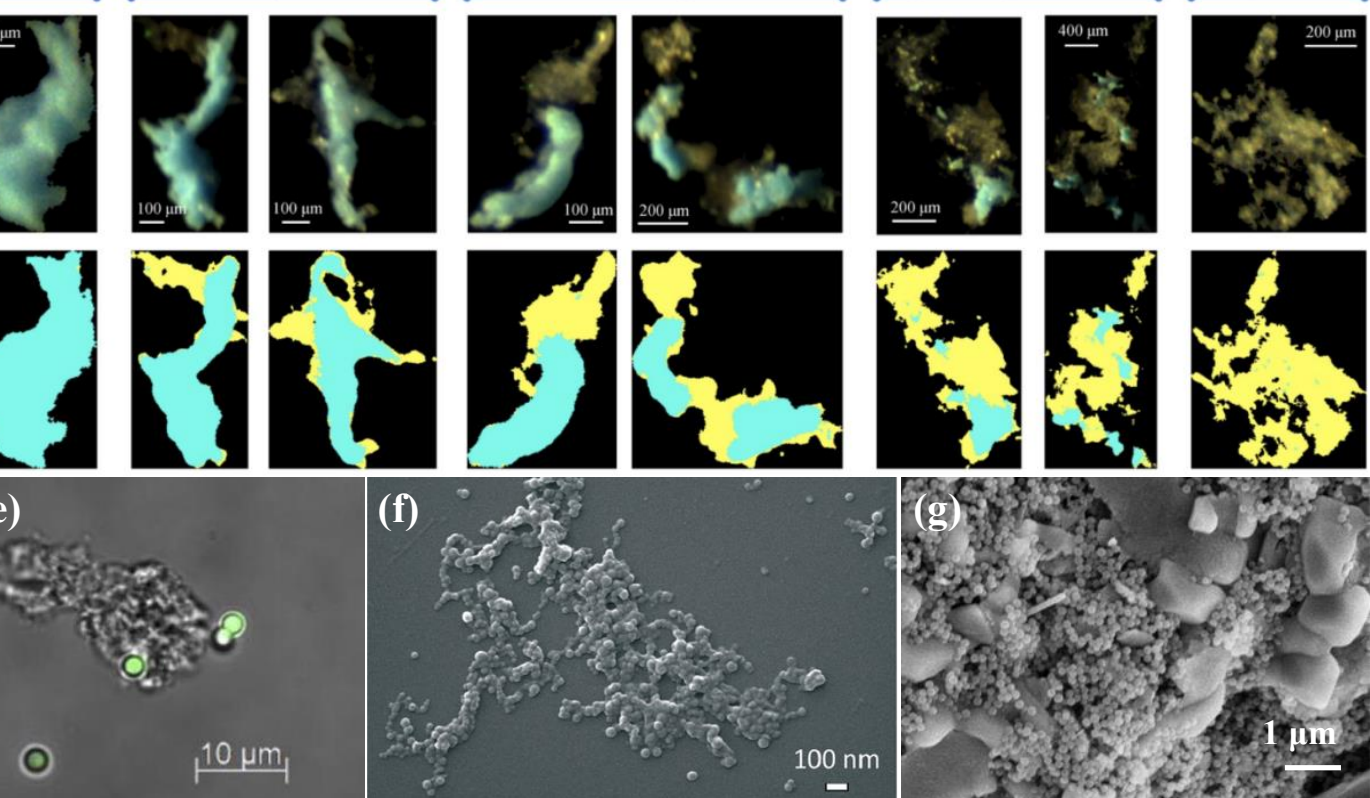

(f)

Fig. 1. Major types of aggregates formed by microplastics (MPs)/nanoplastics (NPs). (a) $0.1 \mathrm{~mm}$ polystyrene MPs (PS MPs) aggregate with Chlorella pyrenoidosa (Mao et al., 2018); (b) $1.0 \mathrm{~mm}$ PS MPs aggregate with Chlorella pyrenoidosa (Mao et al., 2018); (c) $100 \mathrm{~nm}$ PS NPs aggregate with marine microalgae Phaeodactylum tricornutum (Sendra et al., 2019);

(d) Samples

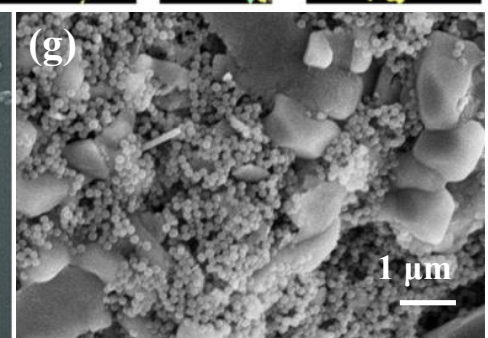
measurement of cell colonization (Bäbler et al., 2020); (e) Micrograph of PS MPs (green) aggregate with bacteria (Long et al., 2017); (f) SEM image of NPs in the presence of alginate (Oriekhova and Stoll, 2018); (g) SEM image of suspended sediments (100-500 $\mu \mathrm{m}$ ) associated PS NPs heteroaggregates (Li et al., 2019). Figures are adapted from references mentioned above with permission.

The aggregation of MPs in aquatic environments has mainly been studied in laboratories with simulated water samples due to the limitation of collection and detection

124 techniques in studying in the field (Oriekhova and Stoll, 2018). Recently, a number of review papers summarized the sampling methods of natural water samples to investigate 
126 the mass and distribution of MPs in water columns (Cutroneo et al., 2020). However, some

127 sampling methods such as the density separation method using electrolyte might change

128 the particle size of MPs (Cutroneo et al., 2020; Prata et al., 2019). Therefore, these methods

129 are not quite applicable for investigating the stability of MPs in water. During

130 characterizing the size distribution of MPs using light-scattering methods, the detection

131 might be hampered by the low concentration of MPs in environmental samples or by the

132 complexity of real environmental media (Praetorius et al., 2020). Only a few studies exist

133 to investigate the aggregation of plastic particles at the micro- and nanometer size fractions

134 in complex matrices, because of the practical and fundamental challenges for isolation and

135 analysis of particulate plastics smaller than $100 \mu \mathrm{m}$ (Gigault et al., 2016; Nguyen et al.,

136 2019). Therefore, the limitations and advantages of various sampling and detection

137 methods have been compared in this review to facilitate the investigation of MP stability

138 in real waters, which has not been well summarized before.

139 The distribution and toxicity of MPs has been the focus of numerous recent works

140 (Wu et al., 2019b). Only a few review papers have paid attention to the research progresses

141 on MP aggregation in water, which are of particular concern, because their changed particle

142 sizes might influence their own transformation, co-transport with other contaminants, and

143 the toxicity to organisms (Yang et al., 2018). It has been demonstrated that the toxicity of

144 PS NPs was higher than that of PS MPs toward Brachionus koreanus, Paracyclopina nana,

145 Daphnia magna, and Tigriopus japonicus (Choi et al., 2019). Till now, studies were 146 primarily focused on the aggregation of spherical polystyrene (PS) MPs with various

147 particle-specific properties (e.g., size and surface coating) (Dong et al., 2018; Romero-

148 Cano et al., 2001; Yu et al., 2019). There remain little data on the aggregation of MPs with 
149 other compositions or shapes. In addition, the water chemical conditions play dominant

150 roles in MP aggregation, but often the effect of a single water chemical condition was taken

151 into consideration in laboratory experiments (Singh et al., 2019). Few reviews discussed

152 the key factors governing MP aggregation and the impact of MP aggregation on the 153 transport of contaminants (Alimi et al., 2018; Gigault et al., 2018; Huffer et al., 2017). Thus,

154 it is necessary to conduct a systematic and comprehensive literature review summarizing 155 the quantitative information and modelling of MP aggregation and environmental impacts 156 of MP aggregation.

157 This paper provides a critical overview of the recent progress in investigating the 158 aggregation of MPs in aquatic environment, especially in the last three years. First, we 159 review the sources and inputs of MPs in aquatic environments. Next, we critically delineate 160 the sampling, visualization and quantification methods for studying MP aggregation. In 161 addition, the main influencing factors of MP aggregation including their own 162 physicochemical properties and environmental conditions are summarized. The potential 163 environmental implications of MP aggregation in water, particularly in the toxicity to 164 organisms and microbial habitation are discussed. Finally, the current gaps in knowledge 165 and suggestions regarding future research on MP aggregation are discussed. The main 166 objectives of this review paper are to: (1) obtain a clear understanding of MP aggregation;

167 (2) propose to establish standardized sampling programs and field studies for investigating 168 MP aggregation; and (3) facilitate a better understanding of potential environmental risks 169 related to MPs aggregation.

\section{Sources and inputs of microplastics in aquatic environments}

MPs are a ubiquitous water contaminant, present in lakes, oceans, and even arctic ice 
172 (Zobkov and Esiukova, 2018). Once in the aquatic environment, wind, run-off, and ocean

173 currents aid in their transport, allowing them to travel well beyond their source. Many of

174 the behaviors (e.g., degradation, weathering, and adsorption of contaminants) associated

175 with MPs are influenced by their pathways of transport and surrounding environment

176 (Chamas et al., 2020). One important behaviour is the aggregation process of MPs upon

177 entering the aquatic environment ( $\mathrm{Li}$ et al., 2018). To fully understand this behavior and

178 associated interactions, the sources and inputs of MPs first need to be discussed.

$179 \quad 2.1$ Primary sources of microplastics in aquatic environments

180 Primary MPs are the manufactured plastic particles with diameters $<5 \mathrm{~mm}$ that

181 perform a specific function within or enhance the requirements of a product (Lei et al.,

182 2017). Examples of primary MPs include those used for or found within personal care

183 products, air-blasting, medicines, and textiles (Fendall and Sewell, 2009). Of all the

184 primary MPs, cosmetic microbeads have received the most attention (Guerranti et al.,

185 2019). Natural exfoliating agents such as crushed fruit stones were originally used within

186 facial scrubs until the cosmetic industry found that exfoliation could be achieved by adding

187 small plastic fragments or beads with low cost (Fendall and Sewell, 2009). Unfortunately,

188 facial scrubs are 'rinsed-off', and consequently, wastewater treatment plants (WWTPs)

189 became a sink for MPs (Murphy et al., 2016). The deluge of research condemning

190 microbeads has resulted in their slow phase-out. Although the Netherlands was the first

191 country to state their intent to ban cosmetic microbeads by 2016 , it was within the United

192 States that the first national legislation, the Microbead-Free Waters Act of 2015, was

193 passed (United States Congress, 2015; Xanthos and Walker, 2017). Air-blasting has also

194 been reported as a source of primary MPs when a less abrasive material is required for 
195 cleaning or paint stripping (Auta et al., 2017). MPs and polymeric film coatings also aid

196 medical drug delivery by acting as a vector and increasing control (Cole et al., 2011).

197 Therefore, the medical industry is also a source of plastic particles (Chamas et al., 2020).

198 Finally, some MPs arise from textile and clothing fibers (Galafassi et al., 2019). However,

199 their classification is somewhat of a grey area as they can be either primary or secondary

200 MPs. The fibers are a result of fabric shredding during manufacture (primary), machine

201 washing of clothes, or after the clothes are discarded to landfill (secondary) (Cole et al., 202 2011).

$203 \quad 2.2$ Secondary sources of microplastics in aquatic environments

204 Alternatively, secondary MPs originate from large plastic material. Human activities 205 or natural weathering processes have resulted in plastics breaking down to micro- or nano206 sized particles (Chamas et al., 2020). Tire wear and tear is a stealthy source of MPs in the 207 environment (Capolupo et al., 2020). Photo-oxidative and thermo-oxidative degradation, 208 mechanical degradation, hydrolysis, and microbial activity are all examples of natural 209 processes that enhance the formation of secondary MPs (Auta et al., 2017). Ultraviolet 210 (UV) light causes photo-oxidative degradation (which can lead to thermo-oxidative 211 degradation), and is a significant factor in the formation of MPs (Andrady, 2011). 212 However, these processes are location dependent, as MPs on land have greater degradation 213 than those in the water (Anderson et al., 2016). Differences in photo-oxidative degradation 214 are primarily due to the reduced temperature and oxygen content caused by the surrounding 215 water. Furthermore, water conditions promote biofilm accumulation onto the surface of the 216 plastic (Andrady, 2011; Bäbler et al., 2020). Although biofilm may reduce UV degradation 217 by forming a barrier to sunlight, certain microorganisms can contribute to the 
218 biodegradation of plastics (Oberbeckmann et al., 2015). Some MPs can breakdown by

219 hydrolysis, but it is not considered a significant mechanism in oceans (Andrady, 2011).

220 Marine conditions will form secondary MPs through wave action (e.g., surf or swash zone),

221 or sediment and wind abrasion (Efimova et al., 2018). Storm conditions further amplify the

222 degradation of plastics in the marine environment.

$223 \quad 2.3$ Inputs of microplastics in aquatic environments

224 Pathways in which MPs enter the aquatic environment include direct input, or from

225 terrestrial or atmospheric routes (Auta et al., 2017). Table 1 provides examples of the 226 average concentrations of MPs sampled from aquatic environments, and their suggested 227 sources. Many products contain plastic, and these can directly end up in waterways, lakes, 228 and oceans through careless handling and littering, especially from recreational water 229 products (e.g., boats, fishing gear, or plastic toys used at the beach) (Sun et al., 2019). They 230 can also indirectly enter aquatic environments through littering, illegal dumping, and poor 231 management of landfills (Cole et al., 2011). Paint chips from boats or ships, and fibers from 232 marine ropes or nets for aquaculture also contribute to water MP pollution (Duis and Coors, 233 2016). Besides serving as a sink for MPs, WWTPs can also be a potential point source of 234 MP exposure for aquatic environments through effluent discharge (Kazour et al., 2019). A 235 study by Edo et al. (2020) predicted that 300 million MP debris were released into a nearby 236 river per day through effluent discharge. Furthermore, MPs can be transported from 237 terrestrial to aquatic environments through run-off, erosion, and wind (Rezaei et al., 2019). 238 Terrestrial inputs of MPs usually contained land applications of biosolids and soil mulching 239 (Campanale et al., 2020). Storm events can increase the concentration of land-based MPs 240 that reach aquatic environments (Eerkes-Medrano et al., 2015). Another input that is 
241 receiving more attention in recent years is the atmospheric deposition of MPs (Murphy et

242 al., 2016). Although higher concentrations of airborne MPs are reported in urban 243 environments, the proximity of coastal cities to water sources could lead to increased levels

244 of MPs in rivers and oceans (Dris et al., 2016). Furthermore, long-range atmospheric 245 transport has been reported as an important factor for the concentration of MPs in the Arctic

246 region (Bergmann et al., 2019). Overall, the extent of MP contamination is evident by the 247 abundance of these particles, even in remote locations such as the Arctic (Bergmann et al., 248 2019; Peeken et al., 2018). 
249 Table 1 Sources and concentrations of microplastics in aquatic environments.

\begin{tabular}{|c|c|c|c|c|c|}
\hline Continent & Location & Suggested Sources & $\begin{array}{l}\text { Average MP } \\
\text { Concentration }\end{array}$ & $\begin{array}{l}\text { Sample } \\
\text { Year }\end{array}$ & Reference \\
\hline Antarctica & Ross Sea & $\begin{array}{l}\text { WWTPs, ship traffic, research activities, } \\
\text { ocean currents, and unknown }\end{array}$ & $0.17 \mathrm{MPs} \cdot \mathrm{m}^{-3}$ & 2010 & (Cincinelli et al., 2017) \\
\hline \multirow[t]{2}{*}{ Asia } & 29 rivers in Japan & $\begin{array}{l}\text { Urban living, WWTPs, airborne (e.g., } \\
\text { winds), and rainfall run-off }\end{array}$ & 0 to $4.94 \mathrm{MPs} \cdot \mathrm{m}^{-3}$ & $2015-2018$ & (Kataoka et al., 2019) \\
\hline & Nakdong River & $\begin{array}{l}\text { Atmospheric fallout, heavy rain, run-off, } \\
\text { urban living, and WWTPs }\end{array}$ & $1555 \mathrm{MPs} \cdot \mathrm{m}^{-3}$ & 2017 & (Eo et al., 2019) \\
\hline Australia & $\begin{array}{l}\text { GMA / Goulburn } \\
\text { River Catchment }\end{array}$ & Natural processes & $0.40 \mathrm{MPs} \cdot \mathrm{L}^{-1}$ & 2018 & (Nan et al., 2020) \\
\hline \multirow[t]{7}{*}{ Europe } & Henares River & WWTPs & $350 \mathrm{MPs} \cdot \mathrm{m}^{-3}$ & 2019 & (Edo et al., 2020) \\
\hline & Le Havre harbor & WWTPs & $\sim 0.1-1.8 \mathrm{MPs} \cdot \mathrm{L}^{-1}$ & 2018 & (Kazour et al., 2019) \\
\hline & Lake Bolsena & $\begin{array}{l}\text { Airborne (e.g., winds), storms, land-based } \\
\text { sources, and WWTPs }\end{array}$ & $3.02 \mathrm{MPs} \cdot \mathrm{m}^{-3}$ & 2014 & (Fischer et al., 2016) \\
\hline & Lake Chiusi & $\begin{array}{l}\text { Water circulation, WWTPs, and local } \\
\text { fisheries }\end{array}$ & $2.22 \mathrm{MPs} \cdot \mathrm{m}^{-3}$ & 2014 & (Fischer et al., 2016) \\
\hline & Ofanto River & $\begin{array}{l}\text { Land-based sources (e.g., agricultural } \\
\text { activities, run-off, and erosion) }\end{array}$ & $\sim 6 \mathrm{MPs} \cdot \mathrm{m}^{-3}$ & $2017-2018$ & $\begin{array}{l}\text { (Campanale et al., } \\
\text { 2020) }\end{array}$ \\
\hline & Rhine River & Urban living, WWTPs, and ship traffic & $892,777 \mathrm{MPs} \cdot \mathrm{km}^{-2}$ & 2014 & (Mani et al., 2015) \\
\hline & River Clyde & WWTPs & $0.25 \mathrm{MPs} \cdot \mathrm{L}^{-1}$ & $\begin{array}{l}\text { Not } \\
\text { mentioned }\end{array}$ & (Murphy et al., 2016) \\
\hline \multirow[t]{3}{*}{$\begin{array}{l}\text { North } \\
\text { America }\end{array}$} & Lake Winnipeg & $\begin{array}{l}\text { Synthetic textiles, secondary MPs, } \\
\text { atmospheric fallout, urban living, and } \\
\text { WWTPs }\end{array}$ & $193,420 \mathrm{MPs} \cdot \mathrm{km}^{-2}$ & 2014-2016 & (Anderson et al., 2017) \\
\hline & Raritan River & WWTPs & $\sim 30 \mathrm{MPs} \cdot \mathrm{m}^{-3}$ & 2015 & $\begin{array}{l}\text { (Estahbanati and } \\
\text { Fahrenfeld, 2016) }\end{array}$ \\
\hline & Chicago River & WWTPs & 17.9 MPs $\cdot \mathrm{m}^{-3}$ & 2013 & $\begin{array}{l}\text { (McCormick et al., } \\
\text { 2014) }\end{array}$ \\
\hline
\end{tabular}




\section{Analytical methods for studying microplastic aggregation in aquatic environment}

The physiochemical properties of MPs including color, shape, density $\left(0.9-2.3 \mathrm{~g} \cdot \mathrm{cm}^{-}\right.$

$253^{3}$ ), and chemical constituents vary significantly in the environment, which increase the 254 difficulty to detect and quantitatively estimate the aggregation state of MPs in real water 255 environment (Stock et al., 2019). Generally, the analytical procedures for MP aggregation 256 in water environments include collection of samples to cover the full-size range of MPs, 257 their visualization, and quantification, as shown in Fig. 2. A convincing analysis of MP 258 aggregation requires standardized methods, which can be useful for understanding the 259 aggregation of MPs in water environments and maximize comparability of investigations.

260 A number of systematic methodologies for this purpose has been compared and 261 summarized in this section. 


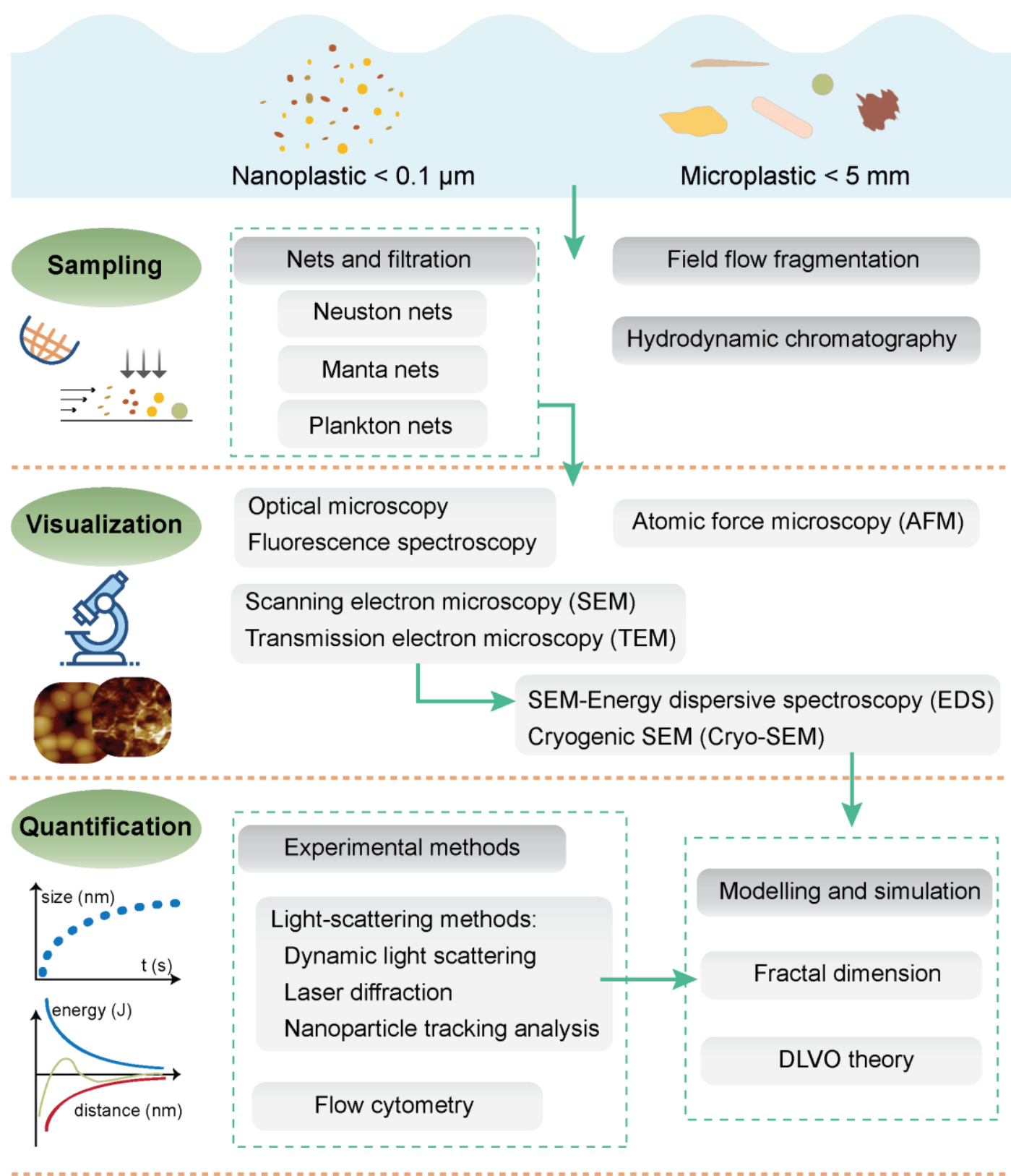

263 Fig. 2. Analysis processes for the aggregation of microplastics (MPs) in water including 264 the sampling, visualization and quantification of MP' particle sizes.

\section{$265 \quad 3.1$ Microplastic sampling methods}

266 Sampling MPs in water environment is the first step for investigating the aggregation 267 of MPs (Pico and Barcelo, 2019). To the best of our knowledge, most studies regarding 268 water sample collection focused on quantifying the content of MPs in natural waters 269 (Cutroneo et al., 2020). Some sampling and separation methods were also suitable for 
270 investigating the aggregation state of MPs in natural waters.

271 The sampling methods of MPs in water can be divided into the selective, bulk sampling, 272 and volume-reduced methods (Wang and Wang, 2018; Zobkov and Esiukova, 2018).

273 Selective sampling refers to direct collection of plastic particles, and they are recognizable 274 by naked eyes (particles between 1 and $5 \mathrm{~mm}$ ) (Silva et al., 2018; Zobkov and Esiukova, 275 2018). This technique is simple but misses some MPs when they are mixed with other 276 debris, or when they have no characteristic shapes, or with ultra-small size (Wang and 277 Wang, 2018). Bulk sampling refers to collecting the entire volume of water samples 278 containing the whole size range of MPs (Silva et al., 2018). Bulk sampling captures 279 relatively small amount of a sample that probably have low concentration of MPs for 280 subsequent processing and detection (Zobkov and Esiukova, 2018). Volume-reduced 281 sampling refers to the condensation of volume of sample, preserving only the portion of 282 interest for further processing (Silva et al., 2018). Therefore, the condensation of MPs 283 improves their mass concentration for stability assessment by instruments (Zobkov and 284 Esiukova, 2018). Selective and bulk sampling methods are usually used to collect sediment 285 samples or water samples, and the volume-reduced method seems to be the most frequently 286 applied approach for sampling water samples (Wang and Wang, 2018). 
287 Table 2 Advantages and disadvantages of various sampling methods for microplastics (MPs) from water

\begin{tabular}{|c|c|c|c|c|}
\hline Method & Size range & Advantages & Disadvantage & Ref. \\
\hline $\begin{array}{l}\text { Neuston nets and } \\
\text { Manta trawls }\end{array}$ & $64-5000 \mu \mathrm{m}$ & $\begin{array}{l}\text { - Sample large volumes of water quickly } \\
\text { - Easy to operate } \\
\text { - Surface water is collected for floating MPs } \\
\text { - Collect large number of MPs }\end{array}$ & $\begin{array}{l}\text { - Clogging of nets by organic or mineral } \\
\text { materials } \\
\text { - Potential contamination by tow ropes or } \\
\text { containers }\end{array}$ & $\begin{array}{l}\text { (Cutroneo et al., 2020; } \\
\text { Hidalgo-Ruz et al., } \\
\text { 2012; Pico et al., 2019) }\end{array}$ \\
\hline Plankton nets & $50-500 \mu \mathrm{m}$ & $\begin{array}{l}\text { - Sample medium volumes of water } \\
\text { - Easy to operate } \\
\text { - Water column is collected } \\
\text { - Quick to use }\end{array}$ & $\begin{array}{l}\text { - Clogging of nets by organic or mineral } \\
\text { materials } \\
\text { - Expensive and time-consuming }\end{array}$ & $\begin{array}{l}\text { (Cutroneo et al., 2020; } \\
\text { Estahbanati and } \\
\text { Fahrenfeld, 2016; Pico } \\
\quad \text { et al., 2019) }\end{array}$ \\
\hline Filtration & $\begin{array}{c}100,20 \text { and } 5 \\
\mu \mathrm{m}\end{array}$ & $\begin{array}{l}\text { - Easy to operate } \\
\text { - Known water volume } \\
\text { - Choice of filter pore sizes }\end{array}$ & $\begin{array}{l}\text { - Obstruction by organic or mineral matter } \\
\text { - Sample low volumes of water } \\
\text { - Potential contamination by the apparatus } \\
\text { - Time consuming and laborious depending on } \\
\text { pore sizes }\end{array}$ & (Stock et al., 2019) \\
\hline $\begin{array}{l}\text { Field flow } \\
\text { fractionation }\end{array}$ & $1 \mathrm{~nm}-100 \mu \mathrm{m}$ & $\begin{array}{l}\text { - No stationary phase improved separation } \\
\text { resolution } \\
\text { - Coupled detectors } \\
\text { - Cover the whole nanometer range }\end{array}$ & $\begin{array}{l}\text { - Hard to operate } \\
\text { - Expensive (advanced instruments) } \\
\text { - Low recovery and analysis speed } \\
\text { - Hard to analyze environmental samples } \\
\text { (need pretreatment) } \\
\text { - Membrane limitation }\end{array}$ & $\begin{array}{l}\text { (Shendruk and Slater, } \\
\text { 2012; Shendruk et al., } \\
\text { 2013) }\end{array}$ \\
\hline $\begin{array}{l}\text { Hydrodynamic } \\
\text { chromatography }\end{array}$ & $5 \mathrm{~nm}-1.2 \mu \mathrm{m}$ & $\begin{array}{l}\text { - Rapid separation of particles } \\
\text { - Higher recovery than field flow fractionation } \\
\text { - Coupled detectors } \\
\text { - Less interaction with stationary phase }\end{array}$ & $\begin{array}{l}\text { - Hard to operate } \\
\text { - Expensive (advanced instruments) } \\
\text { - Low separation resolution }\end{array}$ & $\begin{array}{c}\text { (Blom et al., 2003; } \\
\text { Schwaferts et al., 2019) }\end{array}$ \\
\hline
\end{tabular}




\subsubsection{Nets and filtration}

Nets are the most frequently used devices for sampling MPs from waters (Hidalgo-

291 Ruz et al., 2012; Pico et al., 2019). This method is advantageous for covering large 292 sampling areas, filtering large volumes of water rapidly and concentrating MPs directly 293 during sampling (Stock et al., 2019). However, this method is difficult to apply in narrow 294 spaces such as pot basins, little channel, or in the presence of obstacles (Cutroneo et al., 295 2020). Besides, the mesh size results in the omission of lower size fractions of MPs 296 (Zobkov and Esiukova, 2018). Nets with a mesh width of 50-3000 $\mu \mathrm{m}$ were often used, 297 and $\sim 300 \mu \mathrm{m}$ was the most commonly employed size (Stock et al., 2019). Various types of 298 nets were used across studies (Cutroneo et al., 2020). For example, manta nets and neuston 299 nets with mesh sizes ranging from 64-5000 $\mu \mathrm{m}$ are used for surface water sampling 300 (Cutroneo et al., 2020; Hidalgo-Ruz et al., 2012; Pico et al., 2019). Plankton nets with 301 smaller mesh sizes (c.a. 50-500 $\mu \mathrm{m}$ ) are used for water columns, and can have 30 times 302 higher recovering concentration than manta nets (Prata et al., 2019). For riverbed or seabed 303 sampling, drift or benthic nets that can be attached to the ground were used, while bongo 304 nets were used for sampling from mid-water levels (Stock et al., 2019). Manta nets, neuston 305 nets and plankton nets are the most frequently used devices, and a summary of their 306 comparative performances is given in Table 2.

307 For the filtration method, MPs are separated by passing the water samples over a filter, 308 usually aided by a vacuum. To sort out larger particles before the filtration step, water 309 samples can first be passed through a sieve with $500 \mu \mathrm{m}$ mesh size. The size of MPs 310 retained and the filterable volume are a direct consequence of the filter pore size used (Sun 311 et al., 2019). A promising method is filtering of large volumes of water samples via 
312 cascades of 100, 20 and $5 \mu \mathrm{m}$ filters by directly fractionated pressure filtering (Stock et al.,

313 2019). This method facilitates the simultaneous collection of different size fractions of MPs

314 down to $<5 \mu \mathrm{m}$, and enables a comprehensive resolution of the size spectrum of MPs

315 (Stock et al., 2019; Sun et al., 2019).

316 Nets and filtration methods can maintain the original aggregation state of MPs (Lenz

317 and Labrenz, 2018). However, when these two methods are used, we must balance between

318 the filters' ability to obtain MPs and potential clogging of pores by organic matter, mineral

319 matter and microorganisms (Pico et al., 2019; Stock et al., 2019). The sequential filtration

320 using filters with smaller pore sizes might minimize the clogging (Pico and Barcelo, 2019).

321 In addition, the above two methods would lose the nanometer-sized particles because of

322 their sorption on filters or pore limitations (Sun et al., 2019).

$323 \quad$ 3.1.2 Field flow fractionation (FFF)

324 Beyond the above fractions with large particle sizes, there are smaller plastic 325 fragments that are $<1 \mu \mathrm{m}$ (Pico and Barcelo, 2019). Chromatographic techniques including 326 passive and active separation are typically applied to collect the micro- or nano-sized 327 plastics (Fu et al., 2020). Field flow fractionation (FFF) is a representative active separation 328 technique that can be used for separating MPs with size of $1 \mathrm{~nm}-100 \mu \mathrm{m}$ from water 329 samples (Shendruk and Slater, 2012; Shendruk et al., 2013). Particles such as colloids and 330 macromolecules are size-separated in a channel with parabolic and laminar flow under a 331 perpendicular external field (Shendruk and Slater, 2012). The nature of external fields (i.e., 332 thermal, sedimentation, flow, gravitational, electrical, and magnetic) defines the type of 333 FFF (Messaud et al., 2009). Thermal FFF is suitable for separating polymers based on both 334 molecular weight and composition differences (Runyon and Williams, 2011). 
335 Sedimentation FFF is an alternative to density separation of MPs by electrolytes

336 (Huppertsberg and Knepper, 2018). Flow FFF is most commonly applied method in the

337 separation and analysis of MPs with two modes: normal mode where larger particles have

338 longer retention, whereas this is reversed for larger particles in the steric mode (Gigault et

339 al., 2017; Huppertsberg and Knepper, 2018; Mintenig et al., 2018). Flow FFF technique

340 does not require a stationary phase, which reduces variations or errors caused by the

341 interaction with stationary phase (Shendruk and Slater, 2012). However, low recovery of

342 MPs exists for the flow FFF technique and an advanced instrument is indispensable

343 (Mintenig et al., 2018).

344 Asymmetrical flow field-flow fractionation (AF4) that belongs to flow FFF is 345 primarily used to characterize polymers (Fraunhofer et al., 2004). AF4 was applied to 346 characterize the size distribution of PS NPs and separate them in fish (Correia and 347 Loeschner, 2018; Gigault et al., 2017). AF4 was superior when tissues had auto348 fluorescence property that might interfere with the results of fluorescence microscopy and 349 flow cytometry (FCM) (Correia and Loeschner, 2018). However, AF4 cannot detect 350 polyethylene (PE) NPs in fish due to the interference of light-scattering background, 351 indicating that AF4 requires further adjustment for analyzing different types of NPs 352 (Correia and Loeschner, 2018). AF4 coupled to pyrolysis gas chromatography-mass 353 spectrometry can determine particle sizes and polymer types of MPs, which contributed to 354 a framework development for standardizing the measurement method of MP sizes 355 (Mintenig et al., 2018). Furthermore, hollow fiber flow field-flow fractionation coupled 356 with UV-Vis detector can characterize the particle size distribution of poly(vinyl acetate)

357 NPs in aqueous suspensions (Xiao et al., 2018). 


\subsubsection{Hydrodynamic chromatography (HDC)}

Hydrodynamic chromatography (HDC) is a passive separation technique that can be applied for MP separation from water samples for particle sizes in the range from $10 \mathrm{~nm}$ to

$3611 \mu \mathrm{m}$ (Lespes and Gigault, 2011). The HDC separation principle relies on the size362 dependent exclusion from the wall in a channel where a pressure-driven flow is applied 363 (Lespes and Gigault, 2011). Separating components of sample mixtures is accomplished 364 by parabolic flow velocity gradients that develop within the column between a packed bed 365 filled with media grains (Shendruk and Slater, 2014). The movement of particles with size 366 range from $10 \mathrm{~nm}$ to $1 \mu \mathrm{m}$ under the Brownian motion can be disturbed by media grains 367 (Fu et al., 2020). Small particles receive increasing hydrodynamic effect and van der Waals 368 interactions with media grains and migrate closer to the channel wall, which is subjected 369 to a lower flow velocity (Cejas et al., 2018). Larger particles stay close to the center of the 370 channel where the higher flow velocity causes them to move faster (Liu et al., 2013). Thus 371 small particles elute slower than large particles (Shendruk and Slater, 2014). HDC has been employed to separate MPs and NPs from sediment, seawater and food 373 (Bouwmeester et al., 2015; Chain), 2016). HDC coupled with other detectors has also been 374 used for separation (Philippe et al., 2014; Pirok et al., 2017). For example, HDC coupled 375 with UV-vis detector or ICP-MS was employed to separate PS NPs and several metal 376 nanoparticles in aqueous suspensions (Philippe et al., 2014). HDC combined with size377 exclusion chromatography was used to obtain information on the two-dimensional particle 378 size distribution of the mixed suspensions between PS NPs and polyacrylate NPs (Pirok et 379 al., 2017). HDC showed rapid separation and better recoveries than AF4, but the separation 380 resolution was lower than that of FFF (Revillon, 2000). 


\subsection{Microplastic visualization methods}

After sampling MPs, various visual sorting methods are applied to provide the stability information of MPs as single particles, homoaggregates or heteroaggregates with other materials, such as suspended sediments, algae, and bacteria (Bäbler et al., 2020; Sendra et al., 2019; Sun et al., 2018). This is frequently conducted by direct observation by naked eyes or assisted by a microscope (Silva et al., 2018). For example, the homoaggregation of PE MPs with diameters of 1-5 mm was observed by naked eyes and recorded with a digital camera (Li et al., 2019). To obtain more detailed information on MP aggregation in a water sample, optical microscopy, electron microscopy and scanning probe microscopy are utilized. These microscopes based on different operation modes offer direct access to the geometry and surface characteristics of MP samples (Schwaferts et al., 2019).

\subsubsection{Optical microscopy}

Optical microscopes are usually applied for providing the surface texture, structural information and number of particles with micrometer size (Silva et al., 2018). The heteroaggregates between suspended sediments and PE MPs with diameters $\sim 2 \mathrm{~mm}$ were directly observed by optical microscopes (Li et al., 2019). Techniques such as fluorescence spectroscopy can analyze fluorescently marked particles or materials emitting sufficient fluorescence signal, which could facilitate the investigation of the homoaggregation of MPs or their heteroaggregation with other particles in natural waters (Cunha et al., 2019).

For example, fluorescence spectroscopy was applied to compare the homoaggregation of fluorescent PS NPs and their heteroaggregation with suspended sediment in different water chemical conditions ( $\mathrm{Li}$ et al., 2019). In $500 \mathrm{mM} \mathrm{NaCl}$ solution, fluorescent PS NPs 
404 with diameter of $100 \mathrm{~nm}$ were found to attach onto the surface of suspended sediment with 405 sizes greater than plastic particles $(100 \sim 500 \mu \mathrm{m})$ in the presence or absence of humic acid 406 (HA). By contrast, no homoaggregation or heteroaggregation of PSNPs with suspended 407 sediment was observed in $10 \mathrm{mg} \cdot \mathrm{L}^{-1} \mathrm{HA}$ solutions. This was primarily because HA could 408 be adsorbed onto PS NP and sediment surfaces, imparting electrostatic repulsion and 409 hinderance forces, and thus increased the stability of PS NPs (Tallec et al., 2019). PS and 410 poly(methyl methacrylate) (PMMA) MPs were stained with Nile Red, and applied to 411 characterize their heteroaggregation with microalgae through fluorescence microscopy 412 (Cunha et al., 2019). As shown in Fig. 3, two freshwater microalgae (Scenedesmus sp. and 413 Microcystis panniformis) and two marine microalgae (Gloeocapsa $s$. and Tetraselmis $s p$.) 414 excreted exopolymeric substances (EPS) and colonized MPs. The heteroaggregation 415 degree was related to MP' type, size and density as well as the yield of EPS that was 416 species-specific.

417 However, fluorescence spectroscopy is not applicable for environmental MPs because 418 the dye or fluorophores are not plastic-specific (Schwaferts et al., 2019). Further studies 419 are suggested to focus on the interaction between dyes and MPs, which may facilitate the 420 application of plastic-specific and plastic-sensitive dyes and dye combinations. Another 421 drawback of visual sorting is the size limitation, i.e., particles below a micrometer is 422 difficult to visually discriminate from other materials. Smaller MPs and NPs should 423 generally be sorted out using electron microscopy or scanning probe microscopy (Hale, 424 2017). 

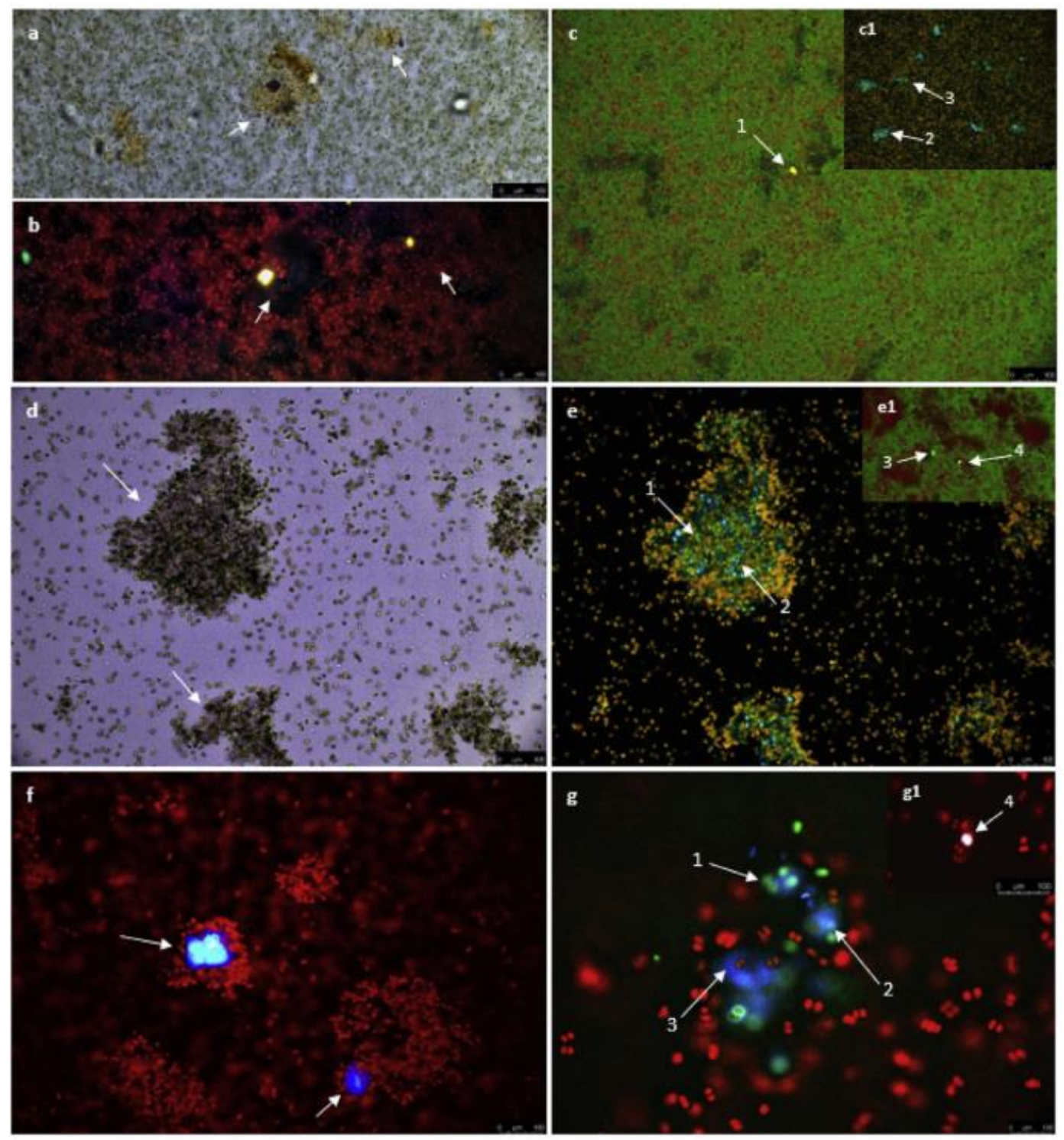

Fig. 3. (a) Bright field micrograph of Microcystis panniformis heteroaggregates; (b) Same micrograph seen in (a), but under DAPI filters, being visible in the incorporation of the 428 fluorescent microplastics (MPs) in the heteroaggregates; (c) Micrograph of Scenedesmus $429 s p$., under I3 filters, showing the abundance of exopolymeric substances (EPS) and the MPs 430 aggregation; (c1) Micrograph of Scenedesmus sp. under DAPI filters, exhibiting 431 aggregation of different MPs. Each arrow pointing at yellow (1) and blue (2) represents polystyrene (PS). Each arrow pointing at the green (3) and purple (4) represents poly(methyl methacrylate) (PMMA); (d) Bright field micrograph of Tetraselmis sp. 434 Heteroaggregates; (e) Same micrograph seen in (d), but under DAPI filters, showing 435 heteroaggregates composed of microalgae (orange) and MPs (blue/green) and EPS; (e1) 436 Micrograph of Tetraselmis sp. heteroaggregates, under I3 filters; (f) Micrograph of 437 Tetraselmis sp. showing the colonization of MPs by the microalga, under DAPI filters; 438 (g/g1) Micrographs of MPs aggregate with Gloeocapsa sp., under DAPI filters. Graph was 439 cited and reproduced from ref. (Cunha et al., 2019) with permission. 


\subsubsection{Electron microscopy}

441 By means of electron beams, the resolution of electron microscopy is much higher 442 than optical microscopy, spanning the range from $1 \mathrm{~nm}$ to millimeters (Schwaferts et al., 443 2019). Scanning electron microscopy (SEM) and transmission electron microscopy (TEM) 444 are often applied to provide high-resolution images, characterize the precise size, and 445 facilitate the differentiation of MP homoaggregates and heteroaggregates with $\mathrm{Fe}_{2} \mathrm{O}_{3}$, 446 alginate, soil particles, and other solid particles (Liu et al., 2019a; Oriekhova and Stoll, 447 2018).

448 The interaction between MPs and microalgae was mostly analyzed by SEM and TEM, 449 as shown in Fig. 1. For example, microalgae (Chlamydomas reinhardtii) colonized MPs 450 (polypropylene (PP) and high-density polyethylene), and the heteroaggregates constituted 451 by microalgae, MPs and EPS were observed by SEM (Lagarde et al., 2016). The formation 452 of heteroaggregation between $\mathrm{TiO}_{2}$ nanoparticles and PS MPs in water was confirmed by 453 SEM, which decreased the toxicity of $\mathrm{TiO}_{2}$ nanoparticles to marine algae Chlorella sp. 454 (Thiagarajan et al., 2019). TEM was applied to characterize the particle size distribution 455 and mean sizes of polyvinyl chloride (PVC) MPs (Zhang et al., 2017). TEM images showed 456 that PS beads attached on the surface of marine bacterium Halomonas alkaliphila led to 457 cellular membrane damage and death (Sun et al., 2018). Although most MPs with a wide 458 size range could be observed by TEM or SEM, these two methods require dry sample 459 preparation, which may induce deposition and interfere with the aggregation state of MPs 460 (Schwaferts et al., 2019). These two methods also need a long analysis time and limited 461 sample sizes or numbers to be studied, which make the results random and thus unreliable 462 (Fu et al., 2020). 
TEM and SEM can be coupled with other instruments to provide details about the MP 464 aggregation state. Energy dispersive spectroscopy (EDS) provides the elemental 465 information of samples via detecting the characteristic X-rays emitted from the elements 466 within the sample by the electron beam (Schwaferts et al., 2019). The SEM-EDS was able 467 to distinguish the homoaggregation of MPs, and heteroaggregation between MPs and DOM 468 or inorganic minerals in real water samples (Fu et al., 2020). Cryogenic SEM (Cryo-SEM) 469 was used to directly observe the aggregation state of PS NPs in the mixture of DOM and 470 salt solution (Cai et al., 2018). As shown in Fig. 4, Cryo-SEM images clearly show the 471 formation of PS NPs-DOM clusters through the bridging effect in the mixture of DOM and $472 \mathrm{FeCl}_{3}$. Cryo-SEM method maintained the morphology of samples in their native 473 environment by rapid freezing, which is a promising tool to reveal the precise information 474 of aggregation state (Kaberova et al., 2020). However, Cryo-SEM may face challenges 475 including low image contrast and low signal to noise ratio. 

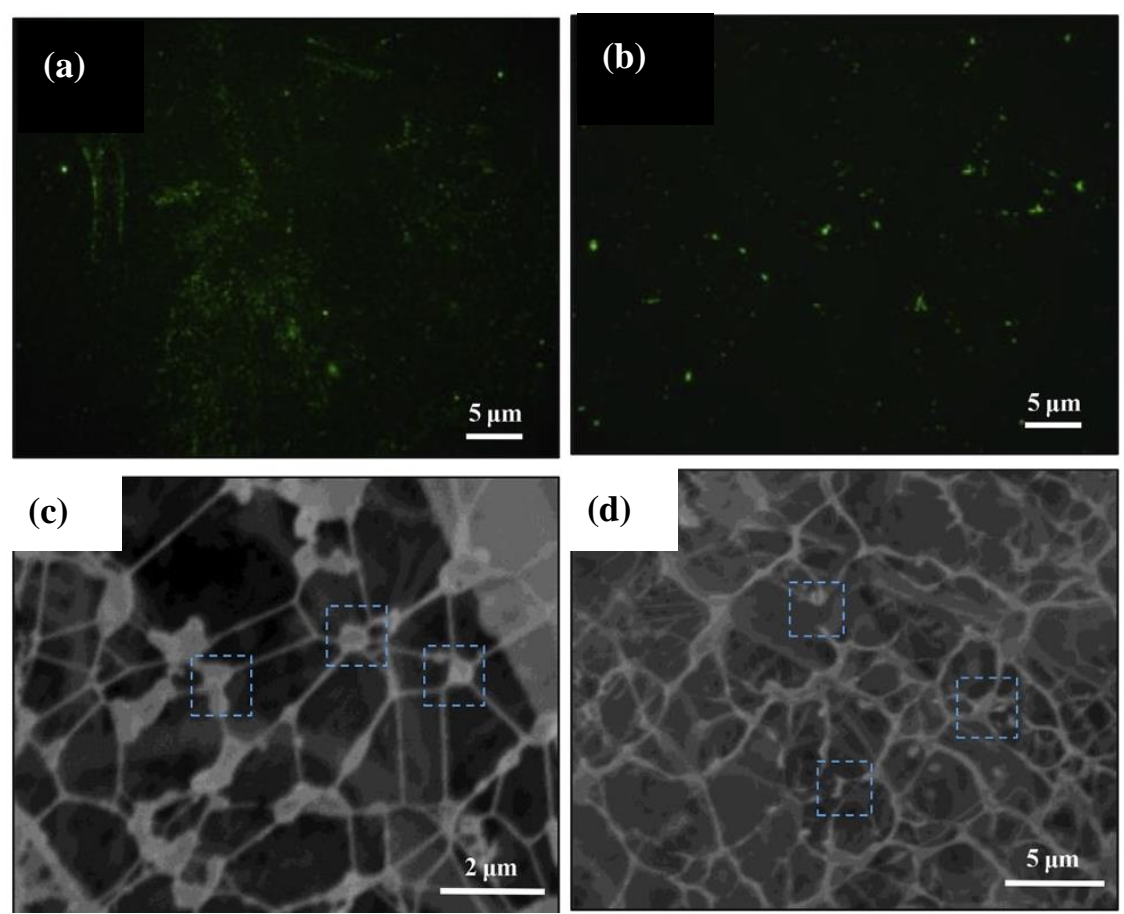

477 Fig. 4. Fluorescence images (a, b) and Cryo-SEM images (c, d) of polystyrene nanoplastics 478 in $1 \mathrm{mM} \mathrm{FeCl}_{3}$ and Suwannee River humic acid (a, c) or Suwannee River fuvic acid (b, d) 479 solutions. Graph was cited and reproduced from ref. (Cai et al., 2018) with permission.

\subsubsection{Scanning probe microscopy}

Scanning probe microscopy, especially atomic force microscopy (AFM), has been identified as one of the most powerful techniques for providing images at nanoscale resolutions (Stawikowska and Livingston, 2013). AFM has been proven useful in the assessment of in-situ surface properties of particles at both microscale and nanoscale (Fu et al., 2020). More importantly, the original dispersed states can be preserved during the

486 AFM analysis process as samples can be placed in vacuum, gaseous, or aqueous 487 environments with desirable conditions, thereby reducing potential experimental artifacts 488 on samples during the preparation process (Fu et al., 2020). AFM provides an effective and 489 non-destructive means for nanoparticle characterization and surface properties analysis 490 such as force profiles, which could also be applied for investigating the stability of MPs 491 (Fu and Zhang, 2018). For example, AFM images indicated that the surface morphology 
492 of particulate plastics was altered by the formation of PP-bacteria heteroaggregates

493 (Kumari et al., 2018). Ruiz-Cabello et al. (2013) employed AFM to measure direct force

494 profiles between carboxyl-modified latex particles (diameter $1.0 \mu \mathrm{m}$ ) in different

495 electrolyte solutions $\left(\mathrm{KCl}, \mathrm{MgCl}_{2}, \mathrm{LaCl}_{3}, \mathrm{ZrCl}_{4}\right)$ and used the observed force profiles to

496 predict their aggregation rates. The force profiles fitted well with Derjaguin-Landau-

497 Verwey-Overbeek (DLVO) theory even though some non-DLVO forces also existed 498 (Trefalt et al., 2017).

499 Visualization methods are commonly applied by most researchers to identify MP 500 aggregation in natural waters. However, visual examination may provide inaccurate 501 information on MP aggregation because it is difficult to differentiate plastic particles from 502 other organic or inorganic particles with similar sizes or shapes (Hale, 2017). Additional 503 techniques such as Raman spectroscopy, Fourier-transform infrared spectroscopy (FTIR), 504 liquid chromatography, and pyrolysis gas chromatography coupled to mass spectrometry 505 are required to be applied to identify the chemical composition of MPs, in addition to the 506 use of visualization methods (Schwaferts et al., 2019).

\section{$507 \quad 3.3$ Microplastic aggregation quantification methods}

\section{$508 \quad$ 3.3.1 Experimental methods}

509 3.3.1.1 Light-scattering methods

510 Light-scattering methods are widely used to quantify the in-situ aggregation behavior 511 of MPs since it is non-destructive (Yu et al., 2019). The most frequently applied light512 scattering method, dynamic light scattering (DLS) instrument, determines the time513 dependent hydrodynamic diameter $\left(D_{h}\right)$ of sample with size range from $0.6 \mathrm{~nm}$ to $6 \mu \mathrm{m}$ 514 under the Brownian motion (Kastner and Perrie, 2016). The zeta potential and 
515 electrophoretic mobility of MPs in an applied electric field can be measured by detecting

516 frequency shifts in the scattered light, which is important for predicting MP aggregation

517 behavior (Kaszuba et al., 2010). So far, there have been a large amount of studies using

518 DLS to measure the aggregation kinetics, aggregate size, and zeta potentials of MPs/NPs

519 in various water chemical conditions (Cai et al., 2018; Yu et al., 2019). Although DLS is

520 fast and simple operation, it has disadvantages such as low resolution and low accuracy for

521 large particles (Wang et al., 2015). DLS is more appropriate for measuring monodisperse

522 suspensions, and has limitation in heteroaggregation studies (Praetorius et al., 2020).

523 Laser diffraction (LD) analyzer based on the static light scattering is used for 524 measuring particles with sizes ranging from submicron $(500 \mathrm{~nm})$ to millimeter $(10 \mathrm{~mm})$,

525 i.e., particles can have sedimentation process and their movement cannot only be governed 526 by Brownian motion (Kastner and Perrie, 2016; Schwaferts et al., 2019). LD relies on time527 averaged intensity measurements and uses volume mean diameter to represent the size of 528 particles (Praetorius et al., 2014). The distribution percentiles $\mathrm{D}(10), \mathrm{D}(50)$ and $\mathrm{D}(90)$ can 529 be reported to analyze variation in particle sizes, representing the $10^{\text {th }}, 50^{\text {th }}$, and $90^{\text {th }}$ 530 percentile of particle size, respectively (Praetorius et al., 2014). The effects of monovalent $531\left(\mathrm{KNO}_{3}, \mathrm{NaNO}_{3}\right.$ and $\left.\mathrm{NaCl}\right)$ and divalent $\left(\mathrm{CaCl}_{2}\right.$ and $\left.\mathrm{BaCl}_{2}\right)$ electrolytes with and without 532 HA in water on the aggregation kinetics of PS MPs (diameter of $17.9 \mu \mathrm{m}$ ) were investigated 533 by LD ( $\mathrm{Li}$ et al., 2018). The results showed that divalent electrolytes were more efficient 534 in destabilizing PS MPs as compared to monovalent electrolytes due to the higher charge 535 neutralization effect of divalent cations (Qu et al., 2010). LD has been proposed as a 536 method to study heteroaggregation kinetics of nanoparticles with larger $\mu$ m-sized 
537 suspended particulate matters, which enables it to measure heteroaggregation of MPs 538 (Praetorius et al., 2020).

539 DLS and LD measurements probe the polydispersity index, of which the value $>0.2$ 540 indicates a very broad size distribution, or heterogeneous or multimodal particle size 541 distributions ( $\mathrm{Li}$ et al., 2019). The aggregation kinetics at an early stage and initial 542 aggregation rate were calculated using the DLS and LD data in most studies (Summers et 543 al., 2018). The initial aggregation rate constant of MPs $(k)$ is proportional to the inverse of 544 MPs concentration $\left(N_{0}\right)$ and the initial increase rate of the $D_{h}$ with time $(t)$, which is 545 calculated by eq 1 (Li et al., 2018).

$$
k \propto \frac{1}{N_{0}}\left(\frac{d D_{h}(t)}{d t}\right)_{t \rightarrow 0}
$$

547 The attachment efficiency $(\alpha)$ is defined as the reciprocal of the stability ratio $(W)$ and is 548 calculated by eq 2 (Praetorius et al., 2020):

$$
\alpha=\frac{1}{W}=\frac{k}{k_{\text {fast }}}=\frac{\frac{1}{N_{0}}\left(\frac{d D_{h}(t)}{d t}\right)_{t \rightarrow 0}}{\frac{1}{\left(N_{0}\right)_{\text {fast }}}\left(\frac{d D_{h}(t)}{d t}\right)_{t \rightarrow 0, \text { fast }}}
$$

where, the subscript "fast" represents a favorable aggregation condition. The numerator 551 and denominator represent the aggregation rate constants under the reaction-limited 552 aggregation regime $(\alpha<1)$ and diffusion-limited aggregation regime $(\alpha=1)$, respectively 553 (Qu et al., 2010). The critical coagulation concentration (CCC) values of MPs can be 554 obtained from $\alpha$. For instance, the CCC values of PS NPs were around $300 \mathrm{mM}$ to $450 \mathrm{mM}$ 555 in monovalent electrolytes (e.g., $\mathrm{NaCl}$ and $\mathrm{KCl}$ ) and around $30 \mathrm{mM}$ in divalent electrolytes 556 (e.g., $\mathrm{CaCl}_{2}$ and $\mathrm{BaCl}_{2}$ ) (Liu et al., 2019b; Yu et al., 2019). While for micro-sized PS MPs, $557 \mathrm{CCC}$ value was smaller compared to PS NPs, such as around $15 \mathrm{mM}$ in $\mathrm{NaCl}, \mathrm{KNO}_{3}$, $558 \mathrm{NaNO}_{3}$, and around $3 \mathrm{mM}$ in $\mathrm{CaCl}_{2}$ and $\mathrm{BaCl}_{2}$ (Li et al., 2018). Besides, the addition of 
559 HA resulted in CCC values of 1.03-2.15 times higher than that without HA, and the CCC

560 values were positively correlated to the HA concentrations ( $\mathrm{Li}$ et al., 2018). This can be

561 attributed to the fact that HA could readily cover the MP surface via adsorption or

562 hydrophobic interaction, which might enhance the stability of MPs due to steric

563 stabilization and/or electrostatic repulsion (Qu et al., 2010).

564 LD or DLS is becoming a preferred technique for particle size measurement compared 565 to SEM, due to their short analytical time, high precision, reproducibility, flexible 566 operation, and easy application (Shekunov et al., 2006). However, significant error in 567 estimating the hydrodynamic particle size for non-spherical particles, such as films and 568 fibers exists in LD or DLS (Shekunov et al., 2006). By contrast, due to direct visualization, 569 SEM is more reliable in analyzing the particle size of non-spherical particles. But 570 characterizing particle size by SEM may have statistical biases associated with particle 571 aggregation during the drying process of sample preparation (Klang et al., 2012). 
572 Table 3 Comparison of light-scattering methods for investigating microplastc aggregation

573 in water

\begin{tabular}{|c|c|c|c|}
\hline Method & DLS & LD & NTA \\
\hline Size range & $0.6 \mathrm{~nm} \sim 6 \mu \mathrm{m}$ & $500 \mathrm{~nm} \sim 10 \mathrm{~mm}$ & $10 \mathrm{~nm} \sim 1000 \mathrm{~nm}$ \\
\hline $\begin{array}{c}\text { Concentration } \\
\text { range }\end{array}$ & Maximum $40 \% \mathrm{w} / \mathrm{v}$ & $\begin{array}{l}\text { Not defined; need low } \\
\text { concentration of sample }\end{array}$ & $10^{7} \sim 10^{10}$ particle $\cdot \mathrm{mL}^{-1}$ \\
\hline Principle & $\begin{array}{l}\text { Scattered light and } \\
\text { Brownian motion }\end{array}$ & Laser diffraction & $\begin{array}{l}\text { Scattered light and } \\
\text { Brownian motion }\end{array}$ \\
\hline $\begin{array}{c}\text { Key } \\
\text { parameters }\end{array}$ & $\begin{array}{l}\text { - Average hydrodynamic } \\
\text { diameter } \\
\text { - Intensity, volume and } \\
\text { number-based particle } \\
\text { size distribution } \\
\text { - Polydispersity index }\end{array}$ & $\begin{array}{l}\text { - Volume mean diameter } \\
\text { - } \mathrm{D}(10), \mathrm{D}(50) \text { and } \mathrm{D}(90) \\
\text { - Polydispersity index }\end{array}$ & $\begin{array}{l}\text { - Particle concentration } \\
\text { - Hydrodynamic diameter }\end{array}$ \\
\hline Advantages & $\begin{array}{l}\text { - Fast and simple } \\
\text { operation } \\
\text { - Aggregation rate } \\
\text { measurement } \\
\text { - Zeta potential } \\
\text { measurement } \\
\text { - Stability ratio } \\
\text { measurement }\end{array}$ & $\begin{array}{l}\text { - Wide size range } \\
\text { - Suitable for } \\
\text { sedimentation } \\
\text { - Aggregation rate } \\
\text { measurement } \\
\text { - More accurate in } \\
\text { heterogeneous system } \\
\text { - Stability ratio } \\
\text { measurement }\end{array}$ & $\begin{array}{l}\text { - Provide particle number } \\
\text { concentration } \\
\text { - Provide size of } \\
\text { individual particles } \\
\text { - Video of particle motion }\end{array}$ \\
\hline Limitations & $\begin{array}{l}\text { - Low accuracy and } \\
\text { resolution for large } \\
\text { particles } \\
\text { - Less suitable for } \\
\text { heteroaggregation studies } \\
\text { - Affected by light } \\
\text { absorption of the } \\
\text { medium }\end{array}$ & $\begin{array}{l}\text { - Affected by light } \\
\text { absorption of the } \\
\text { medium }\end{array}$ & $\begin{array}{l}\text { - The motion trail reduces } \\
\text { accuracy } \\
\text { - Operation difficult } \\
\text { Not suitable for particles } \\
\text { that are too polydisperse } \\
\text { or too close in size }\end{array}$ \\
\hline
\end{tabular}

Nanoparticle tracking analysis (NTA) comes to the forefront when studying poly-

575 dispersed samples where a range of sizes is present, because the NTA data clearly indicate

576 different sizes of particles in suspension (Fu et al., 2020). The detailed comparison of the

577 three light-scattering methods are summarized in Table 3. NTA can simultaneously analyze

578 the particle concentrations and particle size distributions of a sample (Gross et al., 2016).

579 The individual particles from 10 to $1000 \mathrm{~nm}$ can be detected to give particle size

580 distribution data under NTA (Fu et al., 2020; Gross et al., 2016). The formation of NP

581 particles during the degradation of a PS coffee cup lid was observed, and the time-resolved 
582 evolution of particle size distribution of PS NPs was measured by using NTA (Lambert and

583 Wagner, 2016). Additionally, NTA was combined with dark field microscopy to measure 584 the particle size distribution of nanoparticles with the resolution of $c a .20 \mathrm{~nm}$ (Wagner et 585 al., 2014).

\subsubsection{Flow cytometry (FCM)}

FCM detect the light scattering and fluorescence by laser excitation of samples with 588 fluorescence characteristics (natural or staining) in suspension when they pass through a 589 light beam (Adan et al., 2017). FCM is highly sensitive to detect samples with diameter of $590 \quad 0.5-20 \mu \mathrm{m}$ and can be applicable to analyze particles as large as $100 \mu \mathrm{m}$ in diameter 591 (Green et al., 2003). FCM has been widely used in characterizing and distinguishing 592 different cell types in heterogeneous cells, analyzing the size and volume of cells, and 593 analyzing the expression of intracellular molecules (Adan et al., 2017). Some functions are 594 capable of quantifying and characterizing MP aggregation in seawater and study their 595 distribution in the water column (Arias-Andres et al., 2018; Long et al., 2017). For example, 596 the aggregation state of MPs (diameter of $500 \mathrm{~nm}$ ) in seawater was depicted by FCM 597 (Summers et al., 2018). The $500 \mathrm{~nm}$ MPs dispersed and slightly aggregate with the portion 598 of $39.9 \%$. After $24 \mathrm{~h}$ seawater treatment, obvious aggregation could be detected because 599 the proportion of aggregated increased to $93.9 \%$. FCM was also used to observe the 600 heteroaggregation between MPs and organisms such as phytoplankton, bacteria and algae 601 (Arias-Andres et al., 2018; Long et al., 2017). For instance, Long et al. (2017) used FCM 602 to verify the heteroaggregation between fluorescent MPs and phytoplankton (e.g., diatom 603 Chaetoceros neogracile and algae Rhodomonas salina), and measure the concentration of 604 MPs in the aggregates. The FCM approach was also used to quantify the amount of PS 
612 is defined by a power-law relationship between fractal aggregate mass $(m)$ and aggregate 613 radius (r) (Quik et al., 2014).

MPs adsorbed on algal surfaces (Bhattacharya et al., 2010).

\subsubsection{Modelling and simulation for studying MP aggregation}

\subsubsection{Fractal dimension}

Apart from the aggregation kinetics of MPs, an in-depth study of the morphology and structure of MP aggregates is required to determine the toxicity and fate of the aggregates in aquatic environments (Quik et al., 2014). The aggregation of colloids leads to fractal structures that exhibit fractal dimensions $\left(D_{f}\right)$ from zero to three (Li and Logan, 2001). $D_{f}$

$$
m \propto r^{D_{f}}
$$

$D_{f}$ can be determined from LD measurement, or optical sampling and digital image analysis (Meng et al., 2013). $D_{f}$ describes the geometry of aggregates, aggregation rate, and various physical properties such as density and settling velocity of MP aggregates (Li and Logan, 2001; Long et al., 2015). The lower the aggregation rate, the more time particles have to form a denser and more compact structure, and lead to a higher fractal dimension (Meng et al., 2013). Long et al. (2015) used $D_{f}$ to understand the structure of aggregates between PS MPs and phytoplankton or algal species. They found that the heteroaggregate structure turned less fractal after exposure to PS MPs. The correlation between sinking rates and fractal aggregates can be illustrated by a fractal scaling model. In addition, $D_{f}$ has been applied to explain the compactness of MP homoaggregates and chitosan or alginateassociated MP heteroaggregates in salt solution (Ramirez et al., 2016).

\subsubsection{Derjaguin-Landau-Verwey-Overbeek (DLVO) theory}

DLVO theory has been widely employed to understand the relationships between 
628 colloids and their aggregation behavior, and it can be used to explain the stability of MPs

629 in water (Zhang, 2014). The classical DLVO theory considers van der Waals forces and

630 electrostatic forces for yielding the total interaction energies between the material surface

631 in contact (Wang et al., 2015). A particle-particle geometry was employed for

632 homoaggregation between MPs in aqueous environments because most studies used

633 commercial MPs with spheres shape (Cai et al., 2018). When investigating the 634 heteroaggregation between layered clay minerals and NPs in electrolyte solutions, a 635 particle-plate geometry was used because NPs behaved as small particles that deposited on 636 the surface of a large flat plate ( $\mathrm{Li}$ et al., 2019). For the interaction energies between micro 637 or milli-sized MPs in water, a plate-plate geometry fitted well and elucidated the 638 aggregation behavior, such as the homoaggregation of PE MPs (diameter of $1 \mathrm{~mm}$ ). DLVO 639 theory could also be employed to quantify the aggregation kinetics of MPs and estimate 640 their Hamaker constants (Romero-Cano et al., 2001). For example, the Hamaker constants 641 of PS NPs at different aging status derived from DLVO theory were found to decrease from 6423.5 to $1.5 \times 10^{-18} \mathrm{~mJ}$ after 3-day of UV irradiation (Liu et al., 2019b).

643 However, after release into aquatic environments, MPs are likely to undergo aging 644 process and as well as heteroaggregation with DOM, bio-colloids, and inorganic colloids, 645 which modify the surface properties of MPs and introduce non-DLVO forces between 646 particles (Alimi et al., 2018). DLVO theory failed to predict the stability of MPs when non647 DLVO forces (e.g., hydration forces, osmotic pressure, depletion attraction, or steric forces) 648 existed between two approaching particles or in multivalent electrolytes with high 649 concentrations (Wang et al., 2015). In this way, extended DLVO (eDLVO) theory was 650 proposed to model the complex systems. For example, eDLVO theory well explained the 
651 aggregation of UV-aged PS NPs due to aging-induced increase in hydrophilicity (Liu et al., 652 2019a).

\section{4. Factors affecting aggregation of microplastics}

654 The physicochemical properties (e.g., hydrophobicity, surface areas, and surface 655 charge) of MPs may change to some extent under the influence of their own properties, and 656 surrounding pH, light irradiation, solid constituents, and other factors (Jódar-Reyes et al., 657 2006a; Wang et al., 2020). Therefore, the environmental conditions, coexisting solid 658 constituents as well as their own properties could affect the aggregation behavior of MPs

659 in aquatic environments (Jódar-Reyes et al., 2006a; Wu et al., 2019b). Few recent studies 660 pointing out the factors affecting the aggregation of MPs are summarized in Table 4. 


\begin{tabular}{|c|c|c|}
\hline Parameter & Main findings & Ref \\
\hline Particle size & $\begin{array}{l}\text { Smaller MPs are more prone to aggregation at the same conditions. Larger PSNPs-COOH }(200 \mathrm{~nm}) \text { have } \\
\text { higher stability than smaller PSNPs-COOH }(50 \mathrm{~nm}) \text { in } \mathrm{CaCl}_{2} \text { solution. Smaller PS MPs }(0.1-0.6 \mu \mathrm{m}) \\
\text { aggregated rapidly than larger PS MPs }(0.8-1.5 \mu \mathrm{m}) \text { in seawater. }\end{array}$ & $\begin{array}{c}\text { (Dong et al., 2018; Song } \\
\text { et al., 2019) }\end{array}$ \\
\hline Composition & 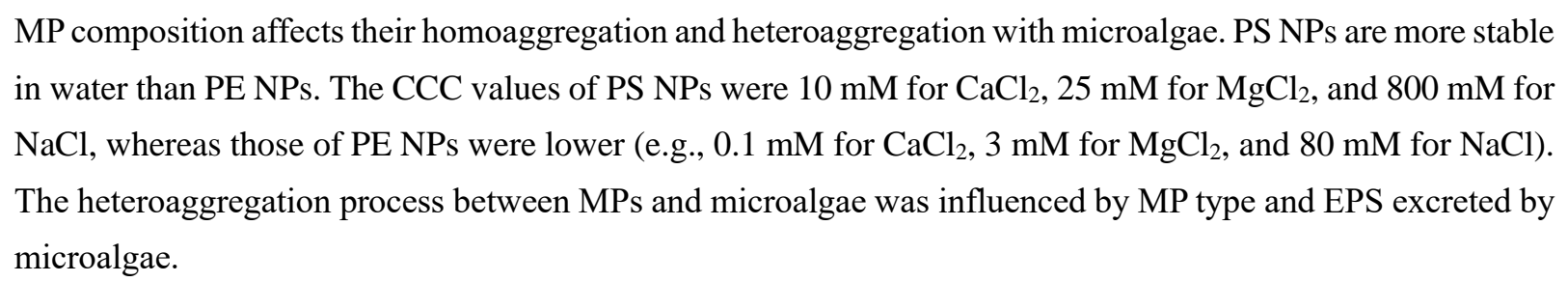 & $\begin{array}{l}\text { (Cunha et al., 2019; } \\
\text { Shams et al., 2020) }\end{array}$ \\
\hline $\begin{array}{c}\text { Surface } \\
\text { modification }\end{array}$ & $\begin{array}{l}\text { Surface modification changed the steric hinderance, hydrophilicity and electrostatic force of plastic particles, } \\
\text { and further influenced the aggregation kinetics. The stability decreased in the order of bare PS NPs }<\text { PSNPs- } \\
\mathrm{NH}_{2}<\text { PSNPs-COOH due to the hydrophilic surface modifications. }\end{array}$ & (Yu et al., 2019) \\
\hline $\mathrm{pH}$ & $\begin{array}{l}\mathrm{pH} \text { influenced the surface charge and electrostatic repulsion of particles via affecting the ionization of surface } \\
\text { groups and adsorption of ions. The aggregation rate of PE NPs remain constant from } \mathrm{pH} 2 \text { to } 9 \text {. The aggregation } \\
\text { of PS NPs with or without surface group modified as the function of } \mathrm{pH} \text { was different among previous studies. }\end{array}$ & $\begin{array}{l}\text { (Romero-Cano et al., } \\
\text { 2001; Shams et al., 2020; } \\
\quad \text { Skaf et al., 2020) }\end{array}$ \\
\hline
\end{tabular}


The concentration, size, and surface physiochemical property of DOM determine its impact on the plastic particle stability and mobility. DOM is one of the most significant factors affecting plastic particle aggregation in waters and may overwhelm the effect of physicochemical properties of plastic particle.

DOM DOM (e.g., humic acid and fulvic acid) destabilized MPs through the bridging effect or surface charge reverse and stabilized MPs through increasing steric repulsion and electrostatic repulsion.

In $\mathrm{NaCl}$ solution, DOM stabilized PS NPs and PS-COOH. In $\mathrm{CaCl}_{2}$ solution, DOM $\left(<5 \mathrm{mg} \cdot \mathrm{C} \cdot \mathrm{L}^{-1}\right)$ inhibited the aggregation of PS NPs and PS-COOH and accelerated their aggregation when DOM concentration was higher than $5 \mathrm{mg} \cdot \mathrm{C} \cdot \mathrm{L}^{-1}$. In $1 \mathrm{mM} \mathrm{FeCl}_{3}$ solution, DOM promoted the aggregation of PS NPs.

Plastic particles (e.g., PE fibers and PS particles) were stabilized by surfactants. Different types of surfactants

Surfactant had different stabilization mechanisms. Anionic/cationic surfactants can add sufficient charges to the particle surface and shield the particle from the effect of solution $\mathrm{pH}$ changes. Nonionic surfactants rarely shifted the surface charges of particle, but provided steric hindrance force to stabilize particles.

Light Light can affect the aggregation of plastic particles through aging process. UV irradiation improved the stability of PSNPs in $\mathrm{NaCl}$ solution and promoted PSNP aggregation in $\mathrm{CaCl}_{2}$ solution.

Phytoplankton, microorganisms (e.g., bacteria and algae), and inorganic colloids (e.g., clay, suspended sediments and $\mathrm{Fe}_{2} \mathrm{O}_{3}$ ) easily adhere to the surfaces of plastic particles and form heteroaggregates. EPS and the size of suspended sediment play an important role in the heteroaggregation processes of MPs. The MP- algae aggregation depends on the species and the physiological state of the algae.
(Song et al., 2019; Wang

et al., 2020; Yu et al.,

(Jódar-Reyes et al., 2006b; Romero-Cano et

al., 2000)

(Liu et al., 2019b)

(Long et al., 2015; Mao et al., 2018; Singh et al., 2019; Zhang et al., 2017) 


\subsection{Physicochemical properties of microplastics}

665

666

667

668

669

670

671

672

673

674

675

676

677

678

679

680

681

682

683

684

685

686

687

\subsubsection{Size}

Surface charge behavior, electronic structure, surface energy, and surface reactivity are dependent on particle size, which can change the interaction forces between two approaching surfaces (Zhang, 2014). For example, smaller particles are easy to aggregate under a given condition than larger particles because of the higher surface energy of the smaller particles (He et al., 2008). In artificial seawater (35 practical salinity units (PSU)), smaller PS MPs $(0.1,0.4,0.6 \mu \mathrm{m})$ aggregated rapidly with sand, while no heteroaggregation occurred between larger PS MPs (0.8 or $1.5 \mu \mathrm{m})$ and sand (Dong et al., 2018). This was primarily because larger PS MPs had higher negative surface charges ( -30 mV) compared to the smaller MPs $(\sim-25 \mathrm{mV})$. DLVO interaction profiles demonstrated that the energy barriers between larger PS MPs and sand (161 k $\mathrm{k}_{\mathrm{B}} \mathrm{T}$ and $\left.296 \mathrm{k}_{\mathrm{B}} \mathrm{T}\right)$ were 1.5-18.5 times higher than that between smaller PS MPs and sand (16 k $\mathrm{k}$ to $\left.108 \mathrm{k}_{\mathrm{B}} \mathrm{T}\right)$. In low salinity seawater (0 - $\left.3.5 \mathrm{PSU}\right)$, neither larger nor smaller PS MPs had interaction with sand because all PS MPs were highly negatively charged with zeta potentials of $-40 \sim-50 \mathrm{mV}$ (Wang et al., 2020). The DLVO interaction profiles showed high interaction energy barriers $\left(\geq 218 \mathrm{k}_{\mathrm{B}} \mathrm{T}\right.$ ) existed between all PS MPs and sand (Dong et al., 2018). Larger carboxyl-modified PS NPs (PSNPs-COOH) (diameter $200 \mathrm{~nm}$ ) with high electrical forces showed higher stability than smaller PSNPs-COOH (diameter $50 \mathrm{~nm}$ ) in a $\mathrm{CaCl}_{2}$ solution, because increasing particle sizes led to the lower Gibbs free energy and reduced adsorption rate of $\mathrm{Ca}^{2+}$ (Song et al., 2019).

\subsubsection{Composition}

Homoaggregation of MPs could differ due to MP chemical composition probably because the Hamaker constant determining van der Waals forces was composition-dependent (Zhang, 2014). Previous studies showed that PS NPs were more stable than PE NPs in a variety of electrolyte solutions $\left(\mathrm{NaCl}, \mathrm{CaCl}_{2}\right.$, and $\mathrm{MgCl}_{2}$ ) (Shams et al., 2020). The effect of $\mathrm{MP}$ composition on their 
heteroaggregation behaviors with microalgae was also investigated. Microalgae could excrete viscous EPS which favored the aggregation with MPs (Long et al., 2015). Cunha et al. (2019) compared the interactions of PMMA MPs and PS MPs with four microalgae, including Microcystis panniformis, Scenedesmus sp, Tetraselmis sp, and Gloeocapsa sp. They found that the formation of MPs-microalgae heteroaggregates depended not only on MP type but also on the content and viscosity of EPS. Since Microcystis panniformis produced the lowest amount of EPS with low viscosity, they were able to form heteroaggregates with PMMA MPs. Gloeocapsa sp. had the capability to aggregate with both PMMA MPs and PS MPs due to the abundant production of viscous EPS. Compared to PE MPs, microalga Chlamydomas reinhardtii were more inclined to form heteroaggregates with PP MPs after 20 days because the EPS produced by the alga had a stronger adhesion to PP MPs than PE MPs (Lagarde et al., 2016).

\subsubsection{Surface coatings}

Functionalization and/or incidental surface coatings are frequently used to stabilize MPs via increasing the electrostatic, steric, or hydrophilic repulsion forces among the particles (Saavedra et al., 2019). For instance, linear poly(ethylene imine) and poly(diallyldimethyl ammonium chloride) improved the stability of sulfate-modified PS MPs in $\mathrm{NaCl}$ solution (Shams et al., 2020). The negatively charged PSNPs-COOH rapidly formed aggregates of $1764 \pm 409 \mathrm{~nm}$ size because of the charge neutralization effect of cations in seawater, whereas positively charged amino-modified PS NPs (PSNPs-NH $)_{2}$ formed aggregates of only $89 \pm 2 \mathrm{~nm}$ size (Alimi et al., 2018). The aggregation rate of amidine-modified PS MPs was much faster than sulfate-modified PS MPs in NaCl solution because the former had a weaker electrostatic repulsion than the latter (Montes Ruiz-Cabello et al., 2015). Furthermore, HA was found to have greater destabilizing effects on PSNPs- $\mathrm{NH}_{2}$ with positive charges than PS NPs and PSNPs-COOH with negative surface charges (Wu et al., 2019a). This was mainly because the negatively charged HA was absorbed on the particle surface, and thus the neutralization 
712 effects were greater for positively charged PSNPs-NH2 (Qu et al., 2010).

\section{$713 \quad 4.2$ Environmental conditions}

\section{$714 \quad$ 4.2.1 Electrolyte concentration and valence}

Electrolyte concentration strongly affects the aggregation behavior of MPs in water by influencing the surface charge of particles (Alimi et al., 2018). For instance, PS NPs of $100 \mathrm{~nm}$ size remained stable in $0.01 \mathrm{mM} \mathrm{FeCl}_{3}$ solution, but the particle size of PS NPs increased rapidly up to 350 $\mathrm{nm}$ with the $\mathrm{FeCl}_{3}$ concentrations increasing to 0.1 and $1 \mathrm{mM}$ (Cai et al., 2018). The enhanced aggregation was mainly due to the compression of the electric double layer and charge shielding on the surface of the particulate plastics, which weakened the repulsive forces between particles (Wu et al., 2019a; Xiao et al., 2018). When the electrolyte concentration exceeded the CCC value, the repulsive interactions were insignificant or absent (Li et al., 2018). As a result, the aggregation rate of MPs changed slightly due to the fact that the aggregation changed from the reaction-limited aggregation regime to the diffusion-limited aggregation regime (Xiao et al., 2018).

The valence of ions is also a key factor that controls the aggregation behavior of MPs in water (Wang et al., 2020). For example, the CCC value of PS NPs in $\mathrm{NaCl}$ solution (800 mM) was 80 -fold and 32-fold higher than those in $\mathrm{CaCl}_{2}(10 \mathrm{mM})$ and $\mathrm{MgCl}_{2}(25 \mathrm{mM})$ solutions, respectively (Shams et al., 2020). The $\mathrm{CCC}$ value of PE NPs in $\mathrm{NaCl}$ solution $(80 \mathrm{mM})$ was 27 -fold higher than that in $\mathrm{MgCl}_{2}$ solution $(3 \mathrm{mM}$ ). The ion-valence-dependent effect usually follows the Schulze-Hardy rule, which suggests that the aggregation state mainly depends on the ionic valence of the opposite charge to that of colloids (Wu et al., 2019a; Xiao et al., 2018). The aggregation rates of sulfonate-modified PS NPs with the diameter of $115 \mathrm{~nm}$ increased in the order of $\mathrm{K}^{+}<\mathrm{Mg}^{2+}<\mathrm{La}^{3+}$ (Schneider et al., 2011).

\subsubsection{Effect of pH}

The $\mathrm{pH}$ of the solution can influence the ionization of surface functional groups and surface charge of MPs, which then determines the magnitude of the electrostatic repulsion, and thus affects 
the aggregation behavior ( $\mathrm{Li}$ et al., 2018). The $\mathrm{pH}$ in the aquatic environment typically remains

737 between 5 and 9 (Chowdhury et al., 2013). Isoelectric point or zero point of charge is the pH at which the surface of particles has a net neutral charge (Bolan et al., 1999; Hierrezuelo et al., 2010). Most MPs have no isoelectric point, or have isoelectric point below 3, which are away from $\mathrm{pH}$ values in natural waters (Li et al., 2018; Skaf et al., 2020; Wang et al., 2020). Thus MPs can be stabilized by electrostatic repulsive forces in the aquatic environment (Hierrezuelo et al., 2010). For example, sulfate-modified PS NPs (100 nm diameter) had no isoelectric point and the particle sizes changed slightly from $\mathrm{pH} 2.3$ to 11 due to strong electrostatic repulsion between particles in ultrapure water (Wang et al., 2020). Similarly, Shams et al. (2020) found that the particle size of PE NPs remained statistically constant from $284.92 \pm 140.56 \mathrm{~nm}$ to $310.29 \pm 165.58 \mathrm{~nm}$ from pH 5 to 9 in $10 \mathrm{mM} \mathrm{NaCl}$ solution due to strong electrostatic repulsive forces. The hydrodynamic diameters of PS NPs were constant (c.a. $900 \mathrm{~nm}$ ) in these conditions. While some studies found that the stability of PS NPs (100 nm diameter) and PSNPs-COOH (303 nm diameter) increased with increasing $\mathrm{pH}$ in $\mathrm{NaCl}$ solution, because more hydroxyl groups could be adsorbed on particle surfaces making the zeta potential values more negative and the electrostatic repulsion higher (Romero-Cano et al., 2001). The discrepancy among these studies may rely on the different production processes, which resulted in the differences of physicochemical properties of the particles such as size, surface chemistry and heterogeneity (Praetorius et al., 2020).

\subsubsection{Effect of DOM}

DOM is ubiquitous in natural waters and can adsorb onto MP surfaces by hydrophobic interaction, ligand exchange, and electrostatic interaction (Tallec et al., 2019). DOM may change the stability of MPs and make them aggregated or dispersed variably in natural waters depending on the valence of ions and functional groups on MP surface (Cai et al., 2018). Adsorbed DOM can impart a negative surface charge and steric forces among particles in aquatic systems, which subsequently improves the 
stability of PS MPs and PSNPs-COOH in the absence of electrolytes (Li et al., 2018; Wu et al., 2019a). HA and fulvic acids (FA) are main fractions of DOM, and are often used as a model DOM (Cai et al., 2018). In ultrapure water, high concentration of HA $\left(30 \mathrm{mg} \cdot \mathrm{L}^{-1}\right)$ induced the aggregation of PSNPs$\mathrm{NH}_{2}$ with positive charges because the addition of HA significantly (ANOVA, $\mathrm{F}=1497, p<0.001$ ) decreased the zeta potential (from $>50 \mathrm{mV}$ to $24.3 \mathrm{mV}$ ) (Tallec et al., 2019). No aggregation of PSNPs$\mathrm{NH}_{2}$ was observed at low concentration of $\mathrm{HA}\left(1\right.$ and $\left.10 \mathrm{mg} \cdot \mathrm{L}^{-1}\right)$ due to the insufficient neutralization effect.

The electrolyte valence played important roles in the aggregation of MPs in DOM (i.e., HA and and electrostatic repulsion to stabilize PS NPs and PSNPs-COOH (Yu et al., 2019). Both HA and FA had negligible effects on the aggregation of negatively charged PS NPs in NaCl solution due to high electrostatic repulsive forces between particles (Cai et al., 2018). HA in the concentration range of 0$50 \mathrm{mg} \cdot \mathrm{L}^{-1}$ promoted the aggregation of positively charged PSNPs- $\mathrm{NH}_{2}$ in $\mathrm{NaCl}$ solution owing to the charge neutralization effect (Wu et al., 2019a). In the presence of divalent or trivalent metal ions, DOM destabilized MPs through the bridge attraction and intermolecular bridging between metal ions and surface functional groups of DOM (Li et al., 2018). For example, in $\mathrm{CaCl}_{2}$ solution, DOM at lowconcentration $\left(<5 \mathrm{mg} \cdot \mathrm{C} \cdot \mathrm{L}^{-1}\right)$ inhibited the aggregation of PS NPs through steric repulsion, but accelerated the aggregation at high DOM concentrations $\left(>5 \mathrm{mg} \cdot \mathrm{C} \cdot \mathrm{L}^{-1}\right)$ through the complexation between $\mathrm{Ca}^{2+}$ and carboxyl groups of DOM (Singh et al., 2019; Yu et al., 2019). Similarly, in $1 \mathrm{mM}$ $\mathrm{FeCl}_{3}$ solution, the complexion reaction between $\mathrm{Fe}^{3+}$ and carboxyl groups of DOM (i.e., HA and FA) adsorbed on PS NP surfaces decreased their stability (Cai et al., 2018).

In the mixture of artificial seawater and HA, the hydrodynamic diameters of PSNPs-COOH and PS NPs increased significantly $(p<0.001)$ with sizes exceeding $1 \mu \mathrm{m}$ in $24 \mathrm{~h}$ due to the charge neutralization effect of divalent cations and bridging effect (Tallec et al., 2019). However, HA 
significantly decreased the hydrodynamic diameters of PS NPs $(p<0.001)$ in artificial seawater in 24 $\mathrm{h}$ to $48 \mathrm{~h}$, causing a stabilizing effect and partial disaggregation presumably due to the increase of steric repulsion forces (Qu et al., 2010). In freshwater, high concentration of nature organic matter, such as alginate and HA, can alleviate the toxicity to zooplankton through increasing stability of MPs or forming an eco-corona on MP surface (Saavedra et al., 2019; Wu et al., 2019a).

\subsubsection{Effect of surfactant}

Surfactants are widely used in domestic and industrial products, and they are frequently used reagents to disperse MPs in water (Skaf et al., 2020). Electrostatic repulsion played a dominant role in increasing colloidal stability, and thereby varying aggregation rates when ionic surfactants covered MPs (Jódar-Reyes et al., 2006b). A cationic surfactant, domiphen bromide, resulted in the aggregation of negatively charged PSNPs-COOH particles due to the charge neutralization effect (Jódar-Reyes et al., 2006b). Similarly, an anionic surfactant, sodium dodecylbenzenesulfonate, promoted the aggregation of positively charged amphoteric PS MPs (diameter around $350 \mathrm{~nm}$ ). In both the above cases, electrostatic repulsion forces were reduced among the plastic particles due to the presence of surfactant molecules (Jódar-Reyes et al., 2006b). Additionally, the adsorption of non-ionic surfactants on latex particles at high surface coverage could act as a steric stabilizer, and thus improve the stability of PS MPs (Romero-Cano et al., 2000).

\subsubsection{Effect of light}

Solar irradiation, especially the UVA fraction of sunlight, was found to change the physicochemical properties (surface polarity and functional groups) of NPs and alter their aggregation behavior in water (Liu et al., 2019b). The stability of PS NPs was improved in NaCl solution but decreased in $\mathrm{CaCl}_{2}$ solution after exposure to UV light. The high stability of PS NPs in $\mathrm{NaCl}$ solution was likely because of the following three reasons: (1) lowered van der Waals attraction between aged PS NPs because of their decreased Hamaker constants; (2) increased electrostatic forces due to 
deprotonation of oxygen-containing functional groups generated on aged PS NPs; and (3) enhanced steric hindrance forces between UV-exposed PS NPs rendered by the leaching organic matter (Liu et al., 2019b). The aggregation of PS NPs was promoted in $\mathrm{CaCl}_{2}$ solution primarily because $\mathrm{Ca}^{2+}$ could complex with oxygen-containing functional groups such as carbonyl and carboxyl groups, that were formed on UV-irradiated PS NP surfaces (Qu et al., 2010).

\subsection{Other factors}

Microorganisms, phytoplankton and suspended sediments widely existing in natural waters can remarkably interfere with the aggregation states of MPs (Long et al., 2015; Zhang and Chen, 2019). The negatively charged algae Chlorella $s p$. was found to form heteroaggregates with positively charged PSNPs- $\mathrm{NH}_{2}$ particles but not with negatively charged PSNPs-COOH (Thiagarajan et al., 2019). Cellulose is a component of the cell wall of many algal species such as Chlorella and Scenedesmus (Bhattacharya et al., 2010). If suspended in water, cellulose can initiate heteroaggregation between algal cells and MPs. Similarly, EPS enhanced the heteroaggregation of PS MPs and PVC MPs with Chlorella pyrenoidosa and Skeletonema costatum cells (Mao et al., 2018; Zhang et al., 2017). In addition to microorganisms, Li et al. (2019) indicated that suspended sediment formed heteroaggregates with PS NPs and promoted settling of plastic particles in $\mathrm{NaCl}$ solution. However, the interaction between PE MPs and suspended sediments was minor, and PE MPs floated on the water surface for 8 months after the addition of $500 \mathrm{mg} \cdot \mathrm{L}^{-1}$ suspended sediments.

\section{Environmental implications of MP aggregation}

Investigating the aggregation behavior of MPs is of great importance to elucidate their potential environmental implications after their release into natural waters (Rummel et al., 2017). Significant consequences concerning the aggregation of MPs are their altered particle sizes and specific surface areas, which subsequently impact their toxicity toward organisms, their own transformations, cotransport with other pollutants, and formation of biofilm. 


\subsection{Transport and transformation of microplastics}

The aggregation of MPs determines their distribution in natural waters (Bhattacharya et al., 2010). Nano- and micro-sized particulate plastics floating on the water surface can form aggregates with microbial communities or plankton, which may affect the density of the plastics and change their depth in natural waters (Alimi et al., 2018). Aggregates of MPs located at different water depths undergo different degrees of weathering from solar irradiation, biological degradation, mechanical wearing, and pyrolysis, which results in different mass losses or degradation rates of the plastic aggregates (Alimi et al., 2018). Solar irradiation plays a primary role in the photodegradation and pyrolysis of plastic aggregates in the upper surface of natural waters (Chatani et al., 2014). The plastic aggregates can absorb sunlight and generate free radicals through impurities, which lead MPs to break into small fragments with low molecular weights (Zhao et al., 2018). Plastic aggregates settling to the seabed are not affected by illumination, but the complex hydrodynamic processes and microorganisms significantly affect the physicochemical properties and fates of the bottom plastic aggregates (Zhao et al., 2018).

\subsection{Toxicity to organisms}

The toxicity of MPs to organisms depends on their aggregate size (Fan et al., 2019). The aggregated MPs could be less bioavailable to aquatic organisms because the toxicity of particles was inversely proportional to size in general (Choi et al., 2019). In natural seawater, PSNPs-NH${ }_{2}$ formed nano-sized aggregates $(<200 \mathrm{~nm})$ inducing death of brine shrimps in $14 \mathrm{~d}\left(\mathrm{LC}_{50}=0.83 \mu \mathrm{g} \cdot \mathrm{mL}^{-1}\right)$ and inhibition of algal growth $\left(\mathrm{EC}_{50}=12.97 \mu \mathrm{g} \cdot \mathrm{mL}^{-1}\right)$ (Bergami et al., 2017). By contrast, PSNPs-COOH rapidly formed micro-sized aggregates $(>1 \mu \mathrm{m})$, thereby greatly reduced the toxicity to brine shrimps $\left(\mathrm{LC}_{50}>10 \mu \mathrm{g} \cdot \mathrm{mL}^{-1}\right)$ or microalgae $\left(\mathrm{EC}_{50}>50 \mu \mathrm{g} \cdot \mathrm{mL}^{-1}\right)$. It should be noted that $\mathrm{MP}$ aggregates outside the organisms could exert negative effect (Wu et al., 2019a; Zhu et al., 2019). For instance, MP aggregates inhibited the photosynthesis process and limited the transfer of nutriment and energy of 
microalgae in marine ecosystem (Zhu et al., 2019). In addition, the MP-biota heteroaggregates could cause physical damage such as split and oxidative stress toward organisms (Choi et al., 2019; Zhu et al., 2019). The positively charged PS NPs were more prone to aggregate with marine bacterium (Halomonas alkaliphile) via electrostatic attraction, which induced higher toxicity than negatively charged PS NPs (Sun et al., 2018).

The aggregate dimensions of MPs in natural waters fall in the range from nanometers to centimeters or larger, and this could lead to their toxicity toward organisms in different layers of water column (Browne et al., 2008; Ward and Kach, 2009). If MPs aggregated slightly, Brownian motion can keep them suspended on the water surface for months or even longer (Li et al., 2019). The suspended or floated plastic aggregates pose negative effect on zooplankton, planktivory, filter feeders or suspension-feeders. Plastic particles with a large degree of aggregation settle quickly and accumulate in the seabed and sediments (Bergami et al., 2017). Colonization of MPs with organisms results in their higher densities and sinking to the benthos (Galloway et al., 2017). They eventually exert toxic effect on deposit feeders and detritivores that inhabit in the seabed. Because many toxic pollutants could be adsorbed on the surface of sinking plastic aggregates, the detoxification effect for organisms living in the water surface could occur, but toxic effects would transfer to the benthic organisms (Zhang et al., 2017).

The regional variation in biotoxicity of MPs can be assessed by toxicity assay of organisms exposed to MPs in the laboratory through three steps (Bergami et al., 2017; Saavedra et al., 2019). First, water samples or aquatic organisms from different layers of natural waters are collected (de Sá et al., 2018). Second, the type, shape, size and concentration of MPs in those field samples are analyzed (Nan et al., 2020). Third, MPs collected in the field or pristine MPs having similar physicochemical properties with those in the field are selected to examine the ecotoxicity of MPs toward model organisms in the laboratory (Sendra et al., 2019; Zhu et al., 2019). In general, the most frequently 
applied model organisms include planktonic crustacean (Daphnia magna) as zooplankton, fish (Danio rerio and Pomatoschistus microps) as organisms in water column, and mollusc (blue mussel M. edulis) as benthic organisms (de Sá et al., 2018).

\subsection{Transport of contaminants}

MPs can transport pollutants in the following two ways. Firstly, the additives, monomers, and non-intentionally added substances (e.g., flame retardants, phthalate, plasticizers and heave metals) can be leached by MPs (Suhrhoff and Scholz-Böttcher, 2016; Xu et al., 2020). Some of these contaminants are extremely harmful toward organisms (Suhrhoff and Scholz-Böttcher, 2016). Secondly, MPs may act as a transport vector for organic pollutants and heavy metals because MPs may adsorb these pollutants on their surfaces (Cole et al., 2011). Aggregation of MPs may alter their particle sizes and surface areas, which is a key factor determining the transport of the released additives and the adsorbed contaminants (Yang et al., 2018). Compared to large aggregates, small aggregates of MPs with larger surface areas and more reactive sites may release more contaminants and degrade faster (Chen et al., 2019). For example, organotin compounds (dimethyltin and dibutyltin) were released from PVC MPs under UV and visible light irradiation, and the released content of organotin by small sized PVC MPs $(10 \mu \mathrm{m})$ was nearly 1000 -fold higher than that by large sized PVC MPs (300 $\mu \mathrm{m})$ after 56-h UV or visible light irradiation (Chen et al., 2019).

\subsection{Microbial habitation and biofilm formation}

Plastic surfaces exhibit hydrophobicity that facilitates DOM adsorption in aquatic ecosystems. Biofilms of microorganisms can then form on plastic surfaces due to abundant carbon and nutrient sources in the DOM (Harrison et al., 2018). Microbial habitation of MPs and subsequent biofilm formation facilitates the aggregation of MPs, which has several implications that include (Fig. 5): (1) degradation of MPs and the associated contaminants; (2) horizontal gene transfer between microorganisms; (3) toxicity of contaminants associated with MPs; and (4) migration or spreading of 
microorganisms especially in aquatic ecosystems (Oberbeckmann et al., 2015; Rummel et al., 2017).

905 Biodegradation of MPs and consequent release of associated organic contaminants are accelerated by certain organisms present in the biofilm. Moreover, there is growing evidence that the microbial habitation in the biofilm can promote gene exchange (Jacquin et al., 2019); so determining the potential of biofilms for providing the surface for anti-microbial resistance gene transfer is important. Adsorption and desorption processes of pollutants on MP surface in water are influenced by factors such as microbial activity, MP weathering and surface area, and interaction with DOM. MPs provide a more robust vehicle than biodegradable biotic substrates for the transport of organisms over long distances, which can facilitate the movement of microorganisms to different ecosystems and 913 potentially introduce invasive and exotic species (Viršek et al., 2017).

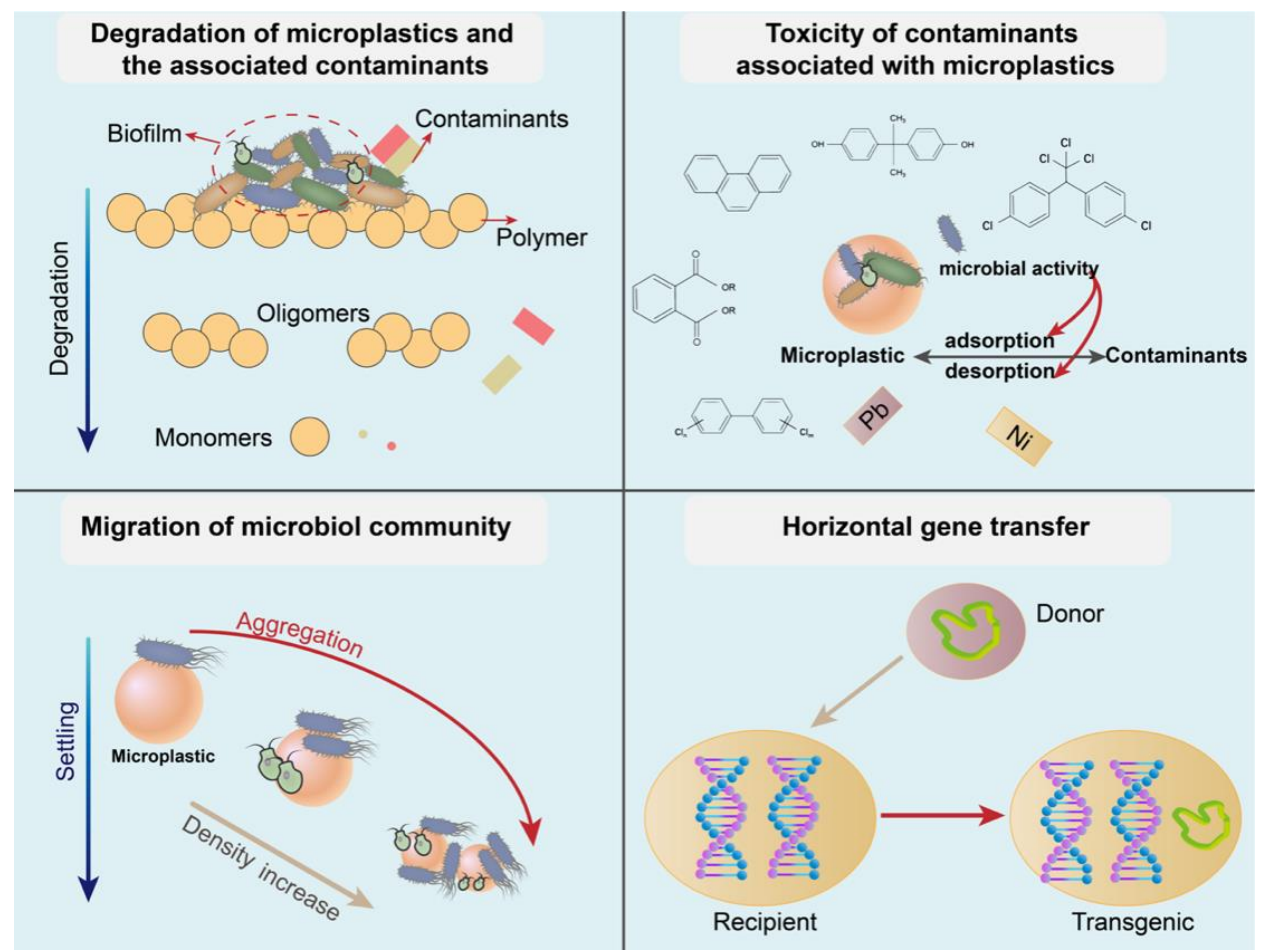

915 Fig. 5. Implications of microbial habitation and biofilm formation on microplastics.

The wide distribution and ecological risk of MPs in aquatic environment are a symptom of mismanagement of plastic wastes, particularly MP debris (Karbalaei et al., 2018). Despite the policies 
and regulations in many countries are implemented to reduce the risk of MPs, the action plans have not considered the potential impacts resulting from the aggregation behaviors of MPs (Auta et al., 2017; Praetorius et al., 2020). In addition, studies have not been conducted extensively on MP aggregation in the field ( $\mathrm{Li}$ et al., 2019). Therefore it is imperative to investigate the aggregation of MPs in environmentally relevant conditions and/or in the field. On the other hand, the need for MP cleaning-up strategy should be considered. Based on systematic investigations of MP aggregation, the removal efficiency of MPs in WWTPs and drinking water treatment via flocculation processes can be promoted (Skaf et al., 2020; Zhang and Chen, 2019). Studies have shown that MP surfaces are suitable substrates for microbial growth, thus biodegradation can be harnessed to degrade MPs (Auta et al., 2017). Manufacturers are encouraged to produce plastics with biodegradable materials (Gallo et al., 2018).

\section{Knowledge gaps and future recommendations}

From numerous studies concerning MPs in the environment, it is evident that although our understanding of MP aggregation in water environments is advancing, currently no standard methods exist for MP separation and identification. Similarly, studies concerning the mobility of MPs in real environments are far from fully understood. To fill these knowledge gaps and fully reveal the influences of plastic pollution on the environment, following most important research issues deserve immediate attention:

\subsection{More field studies}

Most published works focused on the investigations of stability and mobility of MPs in laboratory scales with only a few works studying the aggregation of MPs in environmentally relevant systems, especially in natural surface waters, groundwater, or WWTPs. The natural water system is complex and contains DOM, microorganisms, mixtures of contaminants, and the laboratory research using simulated natural waters may misestimate MPs aggregation behaviors. There is an urgent need to study 
the homoaggregation and heteroaggregation behaviors of primary and secondary MPs in the field to

944 understand how UV weathering and biological processes impact the stability of MPs in natural waters.

945 In addition, river sediments are important sinks for MPs. Further work is therefore needed to better

946 understand the aggregation of MPs in these complex heterogeneous media. Most of the laboratory

947 aggregation studies have been conducted over one hour, but this only provides an initial snapshot of

948 the aggregate. Therefore, it is necessary to perform temporal stability experiments which would allow

949 to evaluate long-term impact of MPs.

\section{$950 \quad 6.2$ Use microplastics in laboratory works representing those in the environment}

Notably, the majority of existing laboratory studies on the aggregation of MPs have used commercial and spherical PS particles with sulfate, amine or carboxyl groups, which are less likely to exist in natural waters (Wang et al., 2020). Most MPs in the environment are expected to have nonspherical shapes (e.g., fibers, strings, pellets, films, thin sheets) and varying compositions (e.g., PE, PP, PVC, polyethylene terephthalate). Therefore, future aggregation research should consider the diversity of MPs to better elucidate their mobility and associated behaviors. In addition, the aggregation behaviors of environmentally relevant secondary MPs comprised of fragments, fibers, films, and rods warrant further examination. Many previous studies on the aggregation of MPs in water have applied extremely high doses of MPs which do not reflect real-world conditions, and resulted in misinterpretation of the results. Researchers are suggested to use environmentally realistic concentration of MPs to yield more realistic estimates of MPs' impacts in aquatic environments.

\subsection{Standardization of identification and quantification methods}

Visual observation is one of the most frequently used techniques for distinguishing between the homoaggregation and heteroaggregation with other solid constituents in water. However, nearly $70 \%$ of small particles, which are characterized visually as MPs, are not confirmed as plastics by chemical detection methods. Therefore, the spectroscopic techniques such as EDS, FTIR, Raman spectroscopy 
are strongly recommended to combine with visual observations for a reliable characterization of MP stability in water environments. In addition, the commonly applied visual observations are insufficient to investigate the aggregation of MPs in environmental samples. Small-sized MPs, especially for the case of MPs $<500 \mu \mathrm{m}$ size, remain poorly understood because of the limitations of existing detection methods and their low resolution for particles at nanoscale. Because the standardized methods for sample collection, identification, and quantification are still in their infancy, comparison of results among different works becomes difficult. Therefore, new research methods should be carefully collated together to formulate standard protocols.

\section{Declaration of Competing Interest}

The authors declare that they have no known competing financial interests or personal relationships that could have appeared to influence the work reported in this paper.

\section{Acknowledgements}

This study was financially supported by the National Natural Science Foundation of China (grant number 21677015) and Hong Kong Research Grants Council (E-PolyU503/17).

\section{References}

Adan, A., Alizada, G., Kiraz, Y., Baran, Y., Nalbant, A., 2017. Flow cytometry: Basic principles and applications. Crit. Rev. Biotechnol. 37, 163-176.

Alimi, O.S., Budarz, J.F., Hernandez, L.M., Tufenkji, N., 2018. Microplastics and nanoplastics in aquatic environments: Aggregation, deposition, and enhanced contaminant transport. Environ. Sci. Technol. 52, 1704-1724.

Anderson, J.C., Park, B.J., Palace, V.P., 2016. Microplastics in aquatic environments: Implications for Canadian ecosystems. Environ. Pollut. 218, 269-280.

Anderson, P.J., Warrack, S., Langen, V., Challis, J.K., Hanson, M.L., Rennie, M.D., 2017. Microplastic contamination in Lake Winnipeg, Canada. Environ. Pollut. 225, 223-231.

Andrady, A.L., 2011. Microplastics in the marine environment. Mar. Pollut. Bull. 62, 1596-1605.

Arias-Andres, M., Klumper, U., Rojas-Jimenez, K., Grossart, H.P., 2018. Microplastic pollution increases gene exchange in aquatic ecosystems. Environ. Pollut. 237, 253-261.

Auta, H.S., Emenike, C.U., Fauziah, S.H., 2017. Distribution and importance of microplastics in the marine environment: A review of the sources, fate, effects, and potential solutions. Environ. Int. 102, 165-176.

Bäbler, M., Nguyen, T.H., Tang, F.H.M., Maggi, F., 2020. Sinking of microbial-associated microplastics in natural waters. 
997 Bergami, E., Pugnalini, S., Vannuccini, M.L., Manfra, L., Faleri, C., Savorelli, F., Dawson, K.A., Corsi, I., 2017. Longterm toxicity of surface-charged polystyrene nanoplastics to marine planktonic species Dunaliella tertiolecta and Artemia franciscana. Aquat. Toxicol. 189, 159-169.

1000 Bergmann, M., Mützel, S., Primpke, S., Tekman, M.B., Trachsel, J., Gerdts, G., 2019. White and wonderful? Microplastics prevail in snow from the Alps to the Arctic. Sci. Adv. 5, eaax1157.

1002 Bhattacharya, P., Lin, S., Turner, J.P., Ke, P.C., 2010. Physical adsorption of charged plastic nanoparticles affects algal photosynthesis. J. Phys. Chem. C 114, 16556-16561.

1004 Blom, M.T., Chmela, E., Oosterbroek, R.E., Tijssen, R., Van Den Berg, A., 2003. On-chip hydrodynamic chromatography separation and detection of nanoparticles and biomolecules. Anal. Chem. 75, 6761-6768.

1006

Bolan, N.S., Naidu, R., Syers, J.K., Tillman, R.W., 1999. Surface charge and solute interactions in soils. Adv. Agron. 67, $87-140$.

1008

Bouwmeester, H., Hollman, P.C., Peters, R.J., 2015. Potential health impact of environmentally released micro-and nanoplastics in the human food production chain: Experiences from nanotoxicology. Environ. Sci. Technol. 49, 8932-8947.

1010 Browne, M.A., Dissanayake, A., Galloway, T.S., Lowe, D.M., Thompson, R.C., 2008. Ingested microscopic plastic translocates to the circulatory system of the mussel, mytilus edulis (L.). Environ. Sci. Technol. 42, 5026-5031.

1012 Cai, L., Hu, L., Shi, H., Ye, J., Zhang, Y., Kim, H., 2018. Effects of inorganic ions and natural organic matter on the aggregation of nanoplastics. Chemosphere 197, 142-151.

1014 Campanale, C., Stock, F., Massarelli, C., Kochleus, C., Bagnuolo, G., Reifferscheid, G., Uricchio, V.F., 2020. Microplastics and their possible sources: The example of Ofanto river in southeast Italy. Environ. Pollut. 258, 113284.

1016 Capolupo, M., Sorensen, L., Jayasena, K.D.R., Booth, A.M., Fabbri, E., 2020. Chemical composition and ecotoxicity of plastic and car tire rubber leachates to aquatic organisms. Water Res. 169, 115270.

1018 Castelvetro, V., Corti, A., Bianchi, S., Ceccarini, A., Manariti, A., Vinciguerra, V., 2020. Quantification of poly(ethylene terephthalate) micro- and nanoparticle contaminants in marine sediments and other environmental matrices. J. Hazard. Mater. 385, 121517. deposition in microchannels. Phys. Rev. E 98, 062606. EFSA CONTAM Panel (EFSA Panel on Contaminants in the Food Chain), 2016. Presence of microplastics and nanoplastics in food, with particular focus on seafood. EFSA Journal 14, 4501-4531. Chamas, A., Moon, H., Zheng, J., Qiu, Y., Tabassum, T., Jang, J.H., Abu-Omar, M., Scott, S.L., Suh, S., 2020. Degradation rates of plastics in the environment. ACS Sustain. Chem. Eng. 8, 3494-3511. manipulate polymer formation, structure, and properties. Polym. Chem-UK. 5, 2187-2201. Chen, C., Chen, L., Yao, Y., Artigas, F., Huang, Q., Zhang, W., 2019. Organotin release from polyvinyl chloride microplastics and concurrent photodegradation in water: Impacts from salinity, dissolved organic matter, and light exposure. Environ. Sci. Technol. 53, 10741-10752.

1032 Choi, J.S., Hong, S.H., Park, J.W., 2019. Evaluation of microplastic toxicity in accordance with different sizes and exposure times in the marine copepod Tigriopus japonicus. Mar. Environ. Res., 104838.

1034 Chowdhury, I., Duch, M.C., Mansukhani, N.D., Hersam, M.C., Bouchard, D., 2013. Colloidal properties and stability of graphene oxide nanomaterials in the aquatic environment. Environ. Sci. Technol. 47, 6288-6296.

1036 Cincinelli, A., Scopetani, C., Chelazzi, D., Lombardini, E., Martellini, T., Katsoyiannis, A., Fossi, M.C., Corsolini, S., 
FTIR. Chemosphere 175, 391-400.

Cole, M., Lindeque, P., Halsband, C., Galloway, T.S., 2011. Microplastics as contaminants in the marine environment: A review. Mar. Pollut. Bull. 62, 2588-2597.

Correia, M., Loeschner, K., 2018. Detection of nanoplastics in food by asymmetric flow field-flow fractionation coupled to multi-angle light scattering: Possibilities, challenges and analytical limitations. Anal. Bioanal. Chem. 410, 5603-5615. Cunha, C., Faria, M., Nogueira, N., Ferreira, A., Cordeiro, N., 2019. Marine vs freshwater microalgae exopolymers as biosolutions to microplastics pollution. Environ. Pollut. 249, 372-380. Microplastics in seawater: Sampling strategies, laboratory methodologies, and identification techniques applied to port environment. Environ. Sci. Pollut. R. 27, 8938-8952. organisms: What do we know and where should we focus our efforts in the future? Sci. Total. Environ. 645, 1029-1039.

Dong, Z., Qiu, Y., Zhang, W., Yang, Z., Wei, L., 2018. Size-dependent transport and retention of micron-sized plastic spheres in natural sand saturated with seawater. Water Res. 143, 518-526.

1052

Dris, R., Gasperi, J., Saad, M., Mirande, C., Tassin, B., 2016. Synthetic fibers in atmospheric fallout: A source of microplastics in the environment? Mar. Pollut. Bull. 104, 290-293.

1054

Duis, K., Coors, A., 2016. Microplastics in the aquatic and terrestrial environment: Sources (with a specific focus on personal care products), fate and effects. Environ. Sci. Eur. 28, 2.

1056

1057 Edo, C., González-Pleiter, M., Leganés, F., Fernández-Piñas, F., Rosal, R., 2020. Fate of microplastics in wastewater treatment plants and their environmental dispersion with effluent and sludge. Environ. Pollut. 259, 113837.

1058 Eerkes-Medrano, D., Thompson, R.C., Aldridge, D.C., 2015. Microplastics in freshwater systems: A review of the emerging threats, identification of knowledge gaps and prioritisation of research needs. Water Res. 75, 63-82.

1060 Efimova, I., Bagaeva, M., Bagaev, A., Kileso, A., Chubarenko, I.P., 2018. Secondary microplastics generation in the sea swash zone with coarse bottom sediments: Laboratory experiments. Front. Mar. Sci. 5, 313.

1062

Eo, S., Hong, S.H., Song, Y.K., Han, G.M., Shim, W.J., 2019. Spatiotemporal distribution and annual load of microplastics

1063 in the Nakdong River, South Korea. Water Res. 160, 228-237.

1064

Estahbanati, S., Fahrenfeld, N.L., 2016. Influence of wastewater treatment plant discharges on microplastic concentrations in surface water. Chemosphere 162, 277-284.

1066

1067

Fan, Z., Zhuang, W., Se, W., Hao, F., Degao, W., 2019. Aquatic behavior and toxicity of polystyrene nanoplastic particles with different functional groups: Complex roles of $\mathrm{pH}$, dissolved organic carbon and divalent cations. Chemosphere 228, 195-203.

1069 Fendall, L.S., Sewell, M.A., 2009. Contributing to marine pollution by washing your face: Microplastics in facial cleansers. Mar. Pollut. Bull. 58, 1225-1228. Feng, L.J., Sun, X.D., Zhu, F.P., 2020. Nanoplastics promote microcystin synthesis and release from cyanobacterial Microcystis aeruginosa. Environ. Sci. Technol. 54, 3386-3394. Fischer, E.K., Paglialonga, L., Czech, E., Tamminga, M., 2016. Microplastic pollution in lakes and lake shoreline sediments - A case study on Lake Bolsena and Lake Chiusi (central Italy). Environ. Pollut. 213, 648-657. Fraunhofer, W., Winter, G., Coester, C., 2004. Asymmetrical flow field-flow fractionation and multiangle light scattering for analysis of gelatin nanoparticle drug carrier systems. Anal. Chem. 76, 1909-1920. Fu, W., Min, J., Jiang, W., Li, Y., Zhang, W., 2020. Separation, characterization and identification of microplastics and nanoplastics in the environment. Sci. Total Environ. 721, 137561.

1079 Fu, W., Zhang, W., 2018. Measurement of the surface hydrophobicity of engineered nanoparticles using an atomic force 
microscope. Phys. Chem. Chem. Phys. 20, 24434-24443.

Galafassi, S., Nizzetto, L., Volta, P., 2019. Plastic sources: A survey across scientific and grey literature for their inventory and relative contribution to microplastics pollution in natural environments, with an emphasis on surface water. Sci. Total. Environ. 693, 133499.

1084

Gallo, F., Fossi, C., Weber, R., Santillo, D., Sousa, J., Ingram, I., Nadal, A., Romano, D., 2018. Marine litter plastics and microplastics and their toxic chemicals components: The need for urgent preventive measures. Environ. Sci. Eur. 30, 13. Galloway, T.S., Cole, M., Lewis, C., 2017. Interactions of microplastic debris throughout the marine ecosystem. Nat. Ecol. Evol. 1, 1-8.

Gigault, J., El Hadri, H., Reynaud, S., Deniau, E., Grassl, B., 2017. Asymmetrical flow field flow fractionation methods to characterize submicron particles: Application to carbon-based aggregates and nanoplastics. Anal. Bioanal. Chem. 409, 6761-6769. Current opinion: What is a nanoplastic? Environ. Pollut. 235, 1030-1034.

Gigault, J., Pedrono, B., Maxit, B., Ter Halle, A., 2016. Marine plastic litter: The unanalyzed nano-fraction. Environmental Science: Nano 3, 346-350.

Green, R.E., Sosik, H.M., Olson, R.J., DuRand, M.D., 2003. Flow cytometric determination of size and complex refractive index for marine particles: Comparison with independent and bulk estimates. Appl. Optics 42, 526-541. Gross, J., Sayle, S., Karow, A.R., Bakowsky, U., Garidel, P., 2016. Nanoparticle tracking analysis of particle size and concentration detection in suspensions of polymer and protein samples: Influence of experimental and data evaluation parameters. Eur. J. Pharm. Biopharm. 104, 30-41.

1100

Guerranti, C., Martellini, T., Perra, G., Scopetani, C., Cincinelli, A., 2019. Microplastics in cosmetics: Environmental issues and needs for global bans. Environ. Toxicol. Pharmacol. 68, 75-79.

1102 Hale, R.C., 2017. Analytical challenges associated with the determination of microplastics in the environment. Anal. Methods-UK 9, 1326-1327.

1104 Harrison, J.P., Hoellein, T.J., Sapp, M., Tagg, A.S., Ju-Nam, Y., Ojeda, J.J. 2018. Microplastic-associated biofilms: a comparison of freshwater and marine environments. Freshwater microplastics. Springer, pp. 181-201. He, Y., Wan, J., Tokunaga, T., 2008. Kinetic stability of hematite nanoparticles: The effect of particle sizes. J. Nanopart. 1107 Res. 10, 321-332.

1108 Hidalgo-Ruz, V., Gutow, L., Thompson, R.C., Thiel, M., 2012. Microplastics in the marine environment: A review of the methods used for identification and quantification. Environ. Sci. Technol. 46, 3060-3075.

1110 Hierrezuelo, J., Sadeghpour, A., Szilagyi, I., Vaccaro, A., Borkovec, M., 2010. Electrostatic stabilization of charged colloidal particles with adsorbed polyelectrolytes of opposite charge. Langmuir 26, 15109-15111.

1112 Huffer, T., Praetorius, A., Wagner, S., von der Kammer, F., Hofmann, T., 2017. Microplastic exposure assessment in aquatic 1113 environments: Learning from similarities and differences to engineered nanoparticles. Environ. Sci. Technol. 51, 249911142507.

1115 Huppertsberg, S., Knepper, T.P., 2018. Instrumental analysis of microplastics-benefits and challenges. Anal. Bioanal. Chem. $1116410,6343-6353$.

1117 Jacquin, J., Cheng, J., Odobel, C., Conan, P., Pujo-pay, M., Jean-Francois, G., 2019. Microbial ecotoxicology of marine 1118 plastic debris: A review on colonization and biodegradation by the 'plastisphere'. Front. microbiol. 10, 865.

1119 Jódar-Reyes, A.B., Martín-Rodríguez, A., Ortega-Vinuesa, J.L., 2006a. Effect of the ionic surfactant concentration on the 1120 stabilization/destabilization of polystyrene colloidal particles. J. Colloid Interf. Sci. 298, 248-257. Jódar-Reyes, A.B., Ortega-Vinuesa, J.L., Martín-Rodríguez, A., 2006b. Electrokinetic behavior and colloidal stability of 
polystyrene latex coated with ionic surfactants. J. Colloid Interf. Sci. 297, 170-181.

1123 Kaberova, Z., Karpushkin, E., Nevoralova, M., Vetrik, M., Slouf, M., Duskova-Smrckova, M., 2020. Microscopic structure of swollen hydrogels by scanning electron and light microscopies: Artifacts and reality. Polymers-Basel 12, 578.

Karbalaei, S., Hanachi, P., Walker, T.R., Cole, M., 2018. Occurrence, sources, human health impacts and mitigation of microplastic pollution. Environ. Sci. Pollut. Res. Int. 25, 36046-36063.

Kastner, E., Perrie, Y. 2016. Particle Size Analysis of Micro and Nanoparticles. Analytical Techniques in the Pharmaceutical Sciences. Springer, pp. 677-699.

Kaszuba, M., Corbett, J., Watson, F.M., Jones, A., 2010. High-concentration zeta potential measurements using lightscattering techniques. Philos. T. R. Soc. A. 368, 4439-4451.

Kataoka, T., Nihei, Y., Kudou, K., Hinata, H., 2019. Assessment of the sources and inflow processes of microplastics in the river environments of Japan. Environ. Pollut. 244, 958-965.

Kazour, M., Terki, S., Rabhi, K., Jemaa, S., Khalaf, G., Amara, R., 2019. Sources of microplastics pollution in the marine environment: Importance of wastewater treatment plant and coastal landfill. Mar. Pollut. Bull. 146, 608-618.

Klang, V., Matsko, N.B., Valenta, C., Hofer, F., 2012. Electron microscopy of nanoemulsions: An essential tool for characterisation and stability assessment. Micron. 43, 85-103.

Kumari, A., Chaudhary, D.R., Jha, B., 2018. Destabilization of polyethylene and polyvinylchloride structure by marine bacterial strain. Environ. Sci. Pollut. R. 26, 1507-1516.

Lagarde, F., Olivier, O., Zanella, M., Daniel, P., Hiard, S., Caruso, A., 2016. Microplastic interactions with freshwater microalgae: Hetero-aggregation and changes in plastic density appear strongly dependent on polymer type. Environ. Pollut. 215, 331-339.

1142

Lambert, S., Wagner, M., 2016. Characterisation of nanoplastics during the degradation of polystyrene. Chemosphere 145, 265-268.

Lei, K., Qiao, F., Liu, Q., Wei, Z., Qi, H., Cui, S., Yue, X., Deng, Y., An, L., 2017. Microplastics releasing from personal care and cosmetic products in China. Mar. Pollut. Bull. 123, 122-126.

Lenz, R., Labrenz, M., 2018. Small microplastic sampling in water: Development of an encapsulated filtration device. Water 10, 1055.

Lespes, G., Gigault, J., 2011. Hyphenated analytical techniques for multidimensional characterisation of submicron particles: A review. Anal. Chim. Acta. 692, 26-41. microplastics and citrate-coated silver nanoparticles in aquatic environments. J. Hazard. Mater. 385, 121601. environment: Complex roles of electrolytes, $\mathrm{pH}$, and natural organic matter. Environ. Pollut. 237, 126-132. plastics and suspended sediment in water: Implications on aggregation and settling. Water Res. 161, 486-495. contaminant-mobilizing ability of nanoplastics in saturated loamy sand. Environ. Sci. Technol. 53, 5805-5815. Liu, L., Veerappan, V., Pu, Q., Cheng, C., Wang, X., Lu, L., Allen, R.D., Guo, G., 2013. High-resolution hydrodynamic chromatographic separation of large DNA using narrow, bare open capillaries: A rapid and economical alternative technology to pulsed-field gel electrophoresis? Anal. Chem. 86, 729-736.

1162 Liu, Y., Hu, Y., Yang, C., Chen, C., Huang, W., Dang, Z., 2019b. Aggregation kinetics of UV irradiated nanoplastics in aquatic environments. Water Res. 163, 114870. 
1164

1165

1166

1167

1168

1169

1170

1171

1172

1173

1174

1175

1176

1177

1178

1179

1180

1181

1182

1183

1184

1185

1186

1187

1188

1189

1190

1191

1192

1193

1194

1195

1196

1197

1198

1199

1200

1201

1202

1203

1204

1205

Long, M., Moriceau, B., Gallinari, M., Lambert, C., Huvet, A., Raffray, J., Soudant, P., 2015. Interactions between microplastics and phytoplankton aggregates: Impact on their respective fates. Mar. Chem. 175, 39-46.

Long, M., Paul-Pont, I., Hegaret, H., Moriceau, B., Lambert, C., Huvet, A., Soudant, P., 2017. Interactions between polystyrene microplastics and marine phytoplankton lead to species-specific hetero-aggregation. Environ. Pollut. 228, $454-$ 463.

Mani, T., Hauk, A., Walter, U., Burkhardt-Holm, P., 2015. Microplastics profile along the Rhine River. Sci. Rep-UK 5, 17988.

Mao, Y., Ai, H., Chen, Y., Zhang, Z., Zeng, P., Kang, L., Li, W., Gu, W., He, Q., Li, H., 2018. Phytoplankton response to polystyrene microplastics: Perspective from an entire growth period. Chemosphere 208, 59-68.

McCormick, A., Hoellein, T.J., Mason, S.A., Schluep, J., Kelly, J.J., 2014. Microplastic is an abundant and distinct microbial habitat in an urban river. Environ. Sci. Technol. 48, 11863-11871.

Meng, Z., Hashmi, S.M., Elimelech, M., 2013. Aggregation rate and fractal dimension of fullerene nanoparticles via simultaneous multiangle static and dynamic light scattering measurement. J. Colloid Interf. Sci. 392, 27-33.

Messaud, F.A., Sanderson, R.D., Runyon, J.R., Otte, T., Pasch, H., Williams, S.K.R., 2009. An overview on field-flow fractionation techniques and their applications in the separation and characterization of polymers. Prog. Polym. Sci. 34, 351-368.

Mintenig, S.M., Bauerlein, P., Koelmans, A.A., Dekker, S.C., van Wezel, A., 2018. Closing the gap between small and smaller: Towards a framework to analyse nano-and microplastics in aqueous environmental samples. Environ. Sci-Nano 5, 1640-1649.

Montes Ruiz-Cabello, F.J., Trefalt, G., Oncsik, T., Szilagyi, I., Maroni, P., Borkovec, M., 2015. Interaction forces and aggregation rates of colloidal latex particles in the presence of monovalent counterions. J. Phys. Chem. B 119, 8184-8193. Murphy, F., Ewins, C., Carbonnier, F., Quinn, B., 2016. Wastewater treatment works (WwTW) as a source of microplastics in the aquatic environment. Environ. Sci. Technol. 50, 5800-5808.

Nan, B., Su, L., Kellar, C., Craig, N.J., Keough, M.J., Pettigrove, V., 2020. Identification of microplastics in surface water and Australian freshwater shrimp Paratya australiensis in Victoria, Australia. Environ. Pollut. 259, 113865.

Nguyen, B., Claveau-Mallet, D., Hernandez, L.M., Xu, E.G., Tufenkji, N., 2019. Separation and analysis of microplastics and nanoplastics in complex environmental samples. Accounts Chem. Res. 52, 858-866.

Oberbeckmann, S., Loder, M.G.J., Labrenz, M., 2015. Marine microplastic-associated biofilms - A review. Environ. Chem. $12,551-562$.

Oriekhova, O., Stoll, S., 2018. Heteroaggregation of nanoplastic particles in the presence of inorganic colloids and natural organic matter. Environ. Sci-Nano 5, 792-799.

Peeken, I., Primpke, S., Beyer, B., Gütermann, J., Katlein, C., Krumpen, T., Bergmann, M., Hehemann, L., Gerdts, G., 2018. Arctic sea ice is an important temporal sink and means of transport for microplastic. Nat. Commun. 9, 1505.

Philippe, A., Gangloff, M., Rakcheev, D., Schaumann, G., 2014. Evaluation of hydrodynamic chromatography coupled with inductively coupled plasma mass spectrometry detector for analysis of colloids in environmental media-effects of colloid composition, coating and shape. Anal. Methods-UK 6, 8722-8728.

Pico, Y., Alfarhan, A., Barcelo, D., 2019. Nano- and microplastic analysis: Focus on their occurrence in freshwater ecosystems and remediation technologies. TrAC-Trend. Anal. Chem. 113, 409-425.

Pico, Y., Barcelo, D., 2019. Analysis and prevention of microplastics pollution in water: Current perspectives and future directions. ACS Omega 4, 6709-6719.

Pirok, B.W., Abdulhussain, N., Aalbers, T., Wouters, B., Peters, R.A., Schoenmakers, P.J., 2017. Nanoparticle analysis by online comprehensive two-dimensional liquid chromatography combining hydrodynamic chromatography and size- 
exclusion chromatography with intermediate sample transformation. Anal. Chem. 89, 9167-9174. Praetorius, A., Badetti, E., Brunelli, A., Clavier, A., Gallego-Urrea, J.A., Gondikas, A., Hassellöv, M., Hofmann, T., Mackevica, A., Marcomini, A., Peijnenburg, W., Quik, J.T.K., Seijo, M., Stoll, S., Tepe, N., Walch, H., von der Kammer, F., 2020. Strategies for determining heteroaggregation attachment efficiencies of engineered nanoparticles in aquatic environments. Environ. Sci-Nano 7, 351-367.

Praetorius, A., Labille, J., Scheringer, M., Thill, A., Hungerbuhler, K., Bottero, J.Y., 2014. Heteroaggregation of titanium dioxide nanoparticles with model natural colloids under environmentally relevant conditions. Environ. Sci. Technol. 48, 10690-10698.

Prata, J.C., da Costa, J.P., Duarte, A.C., Rocha-Santos, T., 2019. Methods for sampling and detection of microplastics in water and sediment: A critical review. TrAC-Trend. Anal. Chem. 110, 150-159.

Qu, X., Hwang, Y.S., Alvarez, P.J.J., Bouchard, D., Li, Q., 2010. UV irradiation and humic acid mediate aggregation of aqueous fullerene $\left(\mathrm{nC}_{60}\right)$ nanoparticles. Environ. Sci. Technol. 44, 7821-7826.

Quik, J., van De Meent, D., Koelmans, A., 2014. Simplifying modeling of nanoparticle aggregation-sedimentation behavior in environmental systems: A theoretical analysis. Water Res. 62, 193-201.

Ramirez, L., Gentile, S.R., Zimmermann, S., 2016. Comparative study of the effect of aluminum chloride, sodium alginate and chitosan on the coagulation of polystyrene micro-plastic particles. J. Colloid Sci. Biotechnol. 5, 190-198.

Revillon, A., 2000. Alternatives to size-exclusion chromatography. J. Liq. Chromatogr. 17, 2991-3023.

Rezaei, M., Riksen, M., Sirjani, E., Sameni, A., Geissen, V., 2019. Wind erosion as a driver for transport of light density microplastics. Sci. Total. Environ. 669, 273-281.

Romero-Cano, M.S., Martin-Rodriguez, A., de Las Nieves, F., 2000. Colloidal stabilization and destabilization of a carboxyl latex by adsorption of Triton X-100. Macromol. Symp. 151, 427-434.

Romero-Cano, M.S., Martín-Rodríguez, A., de las Nieves, F.J., 2001. Electrosteric stabilization of polymer colloids with different functionality. Langmuir 17, 3505-3511.

Ruiz-Cabello, F.J.M., Trefalt, G., Csendes, Z., Sinha, P., Oncsik, T., Szilagyi, I., Maroni, P., Borkovec, M., 2013. Predicting aggregation rates of colloidal particles from direct force measurements. J. Phys. Chem. B 117, 11853-11862.

Rummel, C.D., Jahnke, A., Gorokhova, E., Kühnel, D., Schmitt-Jansen, M., 2017. Impacts of biofilm formation on the fate and potential effects of microplastic in the aquatic environment. Environmen. Sci. Tech. Let. 4, 258-267.

Runyon, J.R., Williams, S.K.R., 2011. Composition and molecular weight analysis of styrene-acrylic copolymers using thermal field-flow fractionation. J. Chromatogr. A 1218, 6774-6779.

Saavedra, J., Stoll, S., Slaveykova, V.I., 2019. Influence of nanoplastic surface charge on eco-corona formation, aggregation and toxicity to freshwater zooplankton. Environ. Pollut. 252, 715-722.

Schneider, C., Hanisch, M., Wedel, B., Jusufi, A., Ballauff, M., 2011. Experimental study of electrostatically stabilized colloidal particles: Colloidal stability and charge reversal. J. Colloid Interf. Sci. 358, 62-67.

Schwaferts, C., Niessner, R., Elsner, M., Ivleva, N.P., 2019. Methods for the analysis of submicrometer- and nanoplastic particles in the environment. TrAC-Trend. Anal. Chem. 112, 52-65.

Sendra, M., Staffieri, E., Yeste, M.P., Moreno-Garrido, I., Gatica, J.M., Corsi, I., Blasco, J., 2019. Are the primary characteristics of polystyrene nanoplastics responsible for toxicity and ad/absorption in the marine diatom Phaeodactylum tricornutum? Environ. Pollut. 249, 610-619.

Shams, M., Alam, I., Chowdhury, I., 2020. Aggregation and stability of nanoscale plastics in aquatic environment. Water Res. 171, 115401.

Shekunov, B.Y., Chattopadhyay, P., Tong, H.H.Y., Chow, A.H.L., 2006. Particle size analysis in pharmaceutics: Principles, methods and applications. Pharm. Res-Dordr 24, 203-227. 
Shendruk, T.N., Slater, G.W., 2012. Operational-modes of field-flow fractionation in microfluidic channels. J. Chromatogr. A $1233,100-108$.

Shendruk, T.N., Slater, G.W., 2014. Hydrodynamic chromatography and field flow fractionation in finite aspect ratio channels. J. Chromatogr. A 1339, 219-223.

Shendruk, T.N., Tahvildari, R., Catafard, N.M., Andrzejewski, L., Gigault, C., Todd, A., Gagne-Dumais, L., Slater, G.W., Godin, M., 2013. Field-flow fractionation and hydrodynamic chromatography on a microfluidic chip. Anal. Chem. 85, 5981-5988.

Silva, A.B., Bastos, A.S., Justino, C.I.L., da Costa, J.P., Duarte, A.C., Rocha-Santos, T.A.P., 2018. Microplastics in the environment: Challenges in analytical chemistry - A review. Anal. Chim. Acta. 1017, 1-19.

Singh, N., Tiwari, E., Khandelwal, N., Darbha, G.K., 2019. Understanding the stability of nanoplastics in aqueous environments: Effect of ionic strength, temperature, dissolved organic matter, clay, and heavy metals. Environ. Sci-Nano 6, 2968-2976.

Skaf, D.W., Punzi, V.L., Rolle, J.T., Kleinberg, K.A., 2020. Removal of micron-sized microplastic particles from simulated drinking water via alum coagulation. Chem. Eng. J. 386, 123807.

Song, Z., Yang, X., Chen, F., Zhao, F., Zhao, Y., Ruan, L., Wang, Y., Yang, Y., 2019. Fate and transport of nanoplastics in complex natural aquifer media: Effect of particle size and surface functionalization. Sci. Total Environ. 669, 120-128.

Stawikowska, J., Livingston, A.G., 2013. Assessment of atomic force microscopy for characterisation of nanofiltration membranes. J. Membrane. Sci. 425, 58-70.

Stock, F., Kochleus, C., Bänsch-Baltruschat, B., Brennholt, N., Reifferscheid, G., 2019. Sampling techniques and preparation methods for microplastic analyses in the aquatic environment - A review. TrAC-Trend. Anal. Chem. 113, 8492.

Suhrhoff, T.J., Scholz-Böttcher, B.M., 2016. Qualitative impact of salinity, UV radiation and turbulence on leaching of organic plastic additives from four common plastics - A lab experiment. Mar. Pollut. Bull. 102, 84-94.

Summers, S., Henry, T., Gutierrez, T., 2018. Agglomeration of nano- and microplastic particles in seawater by autochthonous and de novo-produced sources of exopolymeric substances. Mar. Pollut. Bull. 130, 258-267.

Sun, J., Dai, X., Wang, Q., van Loosdrecht, M.C.M., Ni, B.-J., 2019. Microplastics in wastewater treatment plants: Detection, occurrence and removal. Water Res. 152, 21-37.

Sun, X., Chen, B., Li, Q., Liu, N., Xia, B., Zhu, L., Qu, K., 2018. Toxicities of polystyrene nano- and microplastics toward marine bacterium Halomonas alkaliphila. Sci. Total Environ. 642, 1378-1385.

Tallec, K., Blard, O., Gonzalez-Fernandez, C., Brotons, G., Berchel, M., Soudant, P., Huvet, A., Paul-Pont, I., 2019. Surface functionalization determines behavior of nanoplastic solutions in model aquatic environments. Chemosphere 225, 639646.

Thiagarajan, V., Iswarya, V., Seenivasan, R., Chandrasekaran, N., Mukherjee, A., 2019. Influence of differently functionalized polystyrene microplastics on the toxic effects of $\mathrm{P} 25 \mathrm{TiO}_{2} \mathrm{NPs}$ towards marine algae Chlorella sp. Aquat. Toxicol. 207, 208-216.

Trefalt, G., Palberg, T., Borkovec, M., 2017. Forces between colloidal particles in aqueous solutions containing monovalent and multivalent ions. Curr. Opin. Colloid In. 27, 9-17.

United States Congress (2015) H.R.1321 - Microbead-Free Waters Act of 2015.

Viršek, M.K., Lovšin, M.N., Koren, Š., Kržan, A., Peterlin, M., 2017. Microplastics as a vector for the transport of the bacterial fish pathogen species Aeromonas salmonicida. Mar. Pollut. Bull. 125, 301-309.

Wagner, T., Lipinski, H.-G., Wiemann, M., 2014. Dark field nanoparticle tracking analysis for size characterization of plasmonic and non-plasmonic particles. J. Nanopart. Res. 16, 2419. 
Wang, H., Adeleye, A.S., Huang, Y., Li, F., Keller, A.A., 2015. Heteroaggregation of nanoparticles with biocolloids and geocolloids. Adv. Colloid Interfac. 226, 24-36.

Wang, J., Zhao, X., Wu, A., Tang, Z., Niu, L., Wu, F., Wang, F., Zhao, T., Fu, Z., 2020. Aggregation and stability of sulfatemodified polystyrene nanoplastics in synthetic and natural waters. Environ. Pollut., https://doi.org/10.1016/j.envpol.2020.114240.

Wang, W., Wang, J., 2018. Investigation of microplastics in aquatic environments: An overview of the methods used, from field sampling to laboratory analysis. TrAC-Trend. Anal. Chem. 108, 195-202.

Ward, J.E., Kach, D.J., 2009. Marine aggregates facilitate ingestion of nanoparticles by suspension-feeding bivalves. Mar. Environ. Res. 68, 137-142.

Wu, J., Jiang, R., Lin, W., Ouyang, G., 2019a. Effect of salinity and humic acid on the aggregation and toxicity of polystyrene nanoplastics with different functional groups and charges. Environ. Pollut. 245, 836-843.

Wu, P., Huang, J., Zheng, Y., Yang, Y., Zhang, Y., He, F., Chen, H., Quan, G., Yan, J., Li, T., Gao, B., 2019b. Environmental occurrences, fate, and impacts of microplastics. Ecotox. Environ. Safe. 184, 109612.

Xanthos, D., Walker, T.R., 2017. International policies to reduce plastic marine pollution from single-use plastics (plastic bags and microbeads): A review. Mar. Pollut. Bull. 118, 17-26.

Xiao, Y., Tan, Z., Yin, Y., Guo, X., Xu, J., Wang, B., Fan, H., Liu, J., 2018. Application of hollow fiber flow field-flow fractionation with UV-Vis detection in the rapid characterization and preparation of poly (vinyl acetate) nanoemulsions. Microchem. J. 137, 376-380.

Xu, Z., Xiong, X., Zhao, Y., Xiang, W., Wu, C., 2020. Pollutants delivered every day: Phthalates in plastic express packaging bags and their leaching potential. J. Hazard. Mater. 384, 121282.

Yang, J., Xu, L., Lu, A., Luo, W., Li, J., Chen, W., 2018. Progress in the source and toxicology of micro (nano) plastics in the environment. Environ. Chem. 37, 383-396.

Yu, S., Shen, M., Li, S., Fu, Y., Zhang, D., Liu, H., Liu, J., 2019. Aggregation kinetics of different surface-modified polystyrene nanoparticles in monovalent and divalent electrolytes. Environ. Pollut. 255, 113302.

Zhang, C., Chen, X., Wang, J., Tan, L., 2017. Toxic effects of microplastic on marine microalgae Skeletonema costatum: Interactions between microplastic and algae. Environ. Pollut. 220, 1282-1288.

Zhang, C., Wang, C., Cao, G., Wang, D., Ho, S.-H., 2020. A sustainable solution to plastics pollution: An eco-friendly bioplastic film production from high-salt contained Spirulina sp. residues. J. Hazard. Mater. 388, 121773.

Zhang, W. 2014. Nanoparticle Aggregation: Principles and Modeling. Nanomaterial: Impacts on Cell Biology and Medicine. Springer, pp. 19-43.

Zhang, Z., Chen, Y., 2019. Effects of microplastics on wastewater and sewage sludge treatment and their removal: A review. Chem. Eng. J. 382, 122955.

Zhao, S., Ward, J.E., Danley, M., Mincer, T.J., 2018. Field-based evidence for microplastic in marine aggregates and mussels: Implications for trophic transfer. Environ. Sci. Technol. 52, 11038-11048.

Zhu, Z., Wang, S., Zhao, F., Wang, S., Liu, F., Liu, G., 2019. Joint toxicity of microplastics with triclosan to marine microalgae Skeletonema costatum. Environ. Pollut. 246, 509-517.

Zobkov, M.B., Esiukova, E.E., 2018. Microplastics in a marine environment: Review of methods for sampling, processing, and analyzing microplastics in water, bottom sediments, and coastal deposits. Oceanology 58, 137-143. 